\title{
Piloted Simulator Evaluation Results of New Fault-Tolerant Flight Control Algorithm
}

\author{
T.J.J. Lombaerts*, \\ Delft University of Technology, P.O. Box 5058, 2600 GB Delft, The Netherlands
}

M.H. Smaili

National Aerospace Laboratory (NLR), P.O. Box 90502, 1006 BM Amsterdam, The Netherlands

\author{
O. Stroosma ; Q.P. Chu§, J.A. Mulder, D.A. Joosten," \\ Delft University of Technology, P.O. Box 5058, 2600 GB Delft, The Netherlands
}

\begin{abstract}
A high fidelity aircraft simulation model, reconstructed using the Digital Flight Data Recorder (DFDR) of the 1992 Amsterdam Bijlmermeer aircraft accident (Flight 1862), has been used to evaluate a new Fault-Tolerant Flight Control Algorithm in an online piloted evaluation. This paper focuses on the piloted simulator evaluation results. Reconfiguring control is implemented by making use of Adaptive Nonlinear Dynamic Inversion (ANDI) for manual fly by wire control. After discussing the modular adaptive controller setup, the experiment is described for a piloted simulator evaluation of this innovative reconfigurable control algorithm applied to a damaged civil transport aircraft. The evaluation scenario, measurements and experimental design, as well as the real-time implementation are described. Finally, reconfiguration test results are shown for damaged aircraft models including component as well as structural failures. The evaluation shows that the FTFC algorithm is able to restore conventional control strategies after the aircraft configuration has changed dramatically due to these severe failures. The algorithm supports the pilot after a failure by lowering workload and allowing a safe return to the airport. For most failures, the handling qualities are shown to degrade less with a failure than the baseline classical control system does.
\end{abstract}

\section{Nomenclature}

C dimensionless coefficient

F $\quad$ steering force

I inertia matrix $\left[\mathrm{kgm}^{2}\right]$

$L ; M ; N \quad$ combined aerodynamic and thrust moment around the body $\mathrm{X} / \mathrm{Y} / \mathrm{Z}$ axis $[\mathrm{Nm}]$

$S \quad$ wing area $\left[\mathrm{m}^{2}\right]$

$V \quad$ airspeed $[\mathrm{m} / \mathrm{s}]$

$X ; Y ; Z \quad$ combined aerodynamic and thrust forces along the body $\mathrm{X} / \mathrm{Y} / \mathrm{Z}$ axis $[\mathrm{N}]$

$\bar{c} \quad$ mean aerodynamic chord $[\mathrm{m}]$

$g \quad$ gravity constant $\left[\mathrm{m} / \mathrm{s}^{2}\right]$

$m \quad$ mass $[\mathrm{kg}]$

$p ; q ; r \quad$ roll, pitch and yaw rate around the body $\mathrm{X} / \mathrm{Y} / \mathrm{Z}$ axis $[\mathrm{rad} / \mathrm{s}]$

$u_{b} ; v_{b} ; w_{b} \quad$ airspeed velocity components along body $\mathrm{X} / \mathrm{Y} / \mathrm{Z}$ axis $[\mathrm{m} / \mathrm{s}]$

\footnotetext{
${ }^{*}$ Researcher and Lecturer, Control and Simulation Division, Faculty of Aerospace Engineering, e-mail: t.j.j.lombaerts@tudelft.nl, AIAA student member

${ }^{\dagger}$ Aerospace Engineer, Training Human Factors and Cockpit Operations Department, AIAA member

$\ddagger$ Researcher, Control and Simulation Division, Faculty of Aerospace Engineering, AIAA member

$\S$ Associate professor, Control and Simulation Division, Faculty of Aerospace Engineering, AIAA member

9Professor, Control and Simulation Division, Faculty of Aerospace Engineering, AIAA member

$\| \mathrm{PhD}$ researcher, Delft Center for Systems and Control, AIAA student member
} 


$\begin{array}{ll}u_{e} ; v_{e} ; w_{e} & \text { airspeed velocity components along earth fixed } \mathrm{X} / \mathrm{Y} / \mathrm{Z} \text { axis }[\mathrm{m} / \mathrm{s}] \\ \mathbf{x} & \text { state vector } \\ 0 & \text { constant term } \\ i_{h} & \text { incidence angle of the stabilizer }[\mathrm{rad}] \\ a ; e ; r & \text { aileron, elevator and rudder } \\ \text { comm } & \text { commanded } \\ f_{o} ; f_{i} & \text { outer, inner flaps } \\ l ; m ; n & \text { combined aerodynamic and thrust moment around the body } \mathrm{X} / \mathrm{Y} / \mathrm{Z} \text { axis }[\mathrm{Nm}] \\ l ; r & \text { left,right } \\ T A S & \text { true airspeed } \\ r u ; r l & \text { upper and lower rudders } \\ \text { sp } & \text { spoiler } \\ \text { air } ; \text { ail } ; \text { aor } ; \text { aol } & \text { inner right, inner left, outer right and outer left ailerons } \\ e i r ; e i l ; e o r ; e o l & \text { inner right, inner left, outer right and outer left elevators } \\ \text { Symbol } & \\ \alpha ; \beta ; \gamma & \text { angle of attack, sideslip angle and flightpath angle }[\mathrm{rad}] \\ \delta & \text { control surface deflection }[\mathrm{rad}] \\ \nu & \text { virtual input } \\ \rho & \text { air density }\left[\mathrm{kg} / \mathrm{m}^{3}\right]\end{array}$

\section{Introduction}

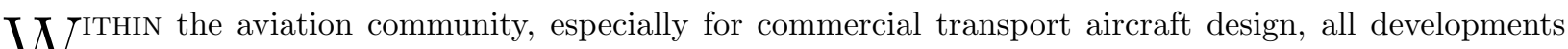
focus on the improvement of safety levels and reducing the risks where critical failures occur. When one analyzes recent aircraft accident statistics, it is clear that a significant portion is attributed to "loss of control in flight". A recent worldwide civil aviation accident survey for the $1989-2003$ period, conducted by the Civil Aviation Authority of the Netherlands (CAA-NL) and based on data from the National Aerospace Laboratory NLR, indicates that this category counts for as much as $17 \%$ of all aircraft accident cases. ${ }^{1,2}$ Contributing to this $17 \%$ of all accidents are among others the following accidents: Japan Airlines flight JL123, where a Boeing 747 lost its fin and its hydraulics, United Airlines flight UA232, where a McDonnell Douglas DC10 lost its hydraulics, El Al flight 1862, where a Boeing 747 lost two engines and partially its hydraulics, and also the DHL cargo flight which suffered a surface-to-air missile impact and also lost all hydraulics. Several situations have occurred where a Boeing 737 has suffered a rudder actuator runaway. There was also an unintentional asymmetric thrust reverser deployment in flight on a Lauda Air Boeing 767 above Thailand, which left the crew a recovery window of only 4 to 6 s. There are also other examples of an American Airlines DC10 losing one of its engines during take off rotation at Chicago O'Hare International Airport and an Air Florida Boeing 737 crashing in the Potomac River in Washington, D.C., due to ice accretion on its wings in adverse weather conditions. All situations have led to a common conclusion: from an aeronautical-technical point of view, with the technology and computing power available at this moment, it might have been possible to recover the aircraft in the previous situations on the condition that nonconventional control strategies would have been available, managing remaining control inputs more effectively. This approach is limited to situations where sufficient aerodynamic and/or thrust control authority is still present after the failure. For example, JL123, UA232 and the DHL aircraft still had some limited steering capability by means of differential thrust. This was the only way left to control these aircraft. These nonconventional control strategies mentioned earlier involve the concept of fault-tolerant control.

A number of new fault detection and isolation methods have been proposed in the literature ${ }^{3-5}$ together

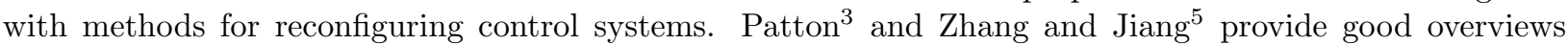
and extensive bibliographic references on the current issues related to the design and implementation of reconfigurable fault tolerant control systems. Reconfigurable flight control systems have been successfully flight tested ${ }^{6-8}$ and evaluated in manned simulations, but currently, no Reconfigurable Fault Tolerant Flight Control (RFTFC) has been certified or applied in either commercial or military aircraft. The earliest flight 
tests of reconfigurable flight control systems were performed during the Self-Repairing Flight Control System (SRFCS) program, ${ }^{8}$ sponsored by the US Air Force Wright Research and Development Center in 1984 . The SRFCS was successfully flight tested by NASA in 1989 and 1990 on an F-15 aircraft at the Dryden Flight Research Center. In 1992, the Intelligent Flight Control (IFC) research program was established to explore the possibilities of using adaptive flight control technology to accommodate unanticipated failures through self-learning neural networks. Within the 1999-2004 Intelligent Flight Control System (IFCS) F-15 program, ${ }^{6}$ sponsored by NASA Dryden Flight Research Center, pre-trained and on-line learning neural networks have been flight tested on the NASA IFCS F-15 testbed. The adaptive neural networks may compensate for changes in the aircraft dynamics due to failures or damage. Piloted simulation studies have been performed at NASA Ames Research Center of Integrated Neural Flight and Propulsion Control Systems (INFPCS) in which neural flight control architectures are combined with Propulsion Controlled Aircraft (PCA) technology. The evaluation successfully demonstrated the benefits of intelligent adaptive control. ${ }^{9}$ Subsequent evaluations are planned to further validate the IFC technologies on a C-17 testbed. Adaptive neural network based technology was further investigated in the Reconfigurable Control for Tailless Aircraft (RESTORE) program in which reconfigurable control design methods were applied. ${ }^{10,11}$ Also at Delft University of Technology, considerable research efforts are being made in this field of Failure Detection and Isolation (FDI) and Fault Tolerant Flight Control (FTFC), among others by means of subspace predictive control, ${ }^{12}$ adaptive model predictive control, ${ }^{13}$ reinforcement learning, ${ }^{14}$ adaptive backstepping, ${ }^{15-17}$ and neural adaptive control. ${ }^{18}$ However, the approach as elaborated in this paper uses an alternative approach, where focus is placed on the use of mathematical representations based on flight dynamics. All quantities and variables which appear in the model have a physical meaning and thus are interpretable in this approach, and one avoids black and grey box models where the content has no clear physical meaning. Besides the fact that this is a more transparent approach, allowing the designers and engineers to interpret data in each step, it is assumed that these physical models will facilitate certification for eventual future real life applications, because monitoring of data is more meaningful.

Pilot evaluations of Fault Tolerant Controllers have been organised before. ${ }^{7,19}$ Handling quality evaluations have been discussed of a reconfigurable control law on the X-36 tailless advanced fighter aircraft (TAFA) for a pitch capture, bank capture and a $360^{\circ}$ roll manoeuvre task. ${ }^{19}$ Handling qualities as well as workload have been analysed for a pitch down manoeuvre in order to evaluate Fault Detection, Isolation and Reconfiguration Algorithms for a Civil Transport Aircraft. ${ }^{7}$ However, the handling quality and workload assessment in this paper are based upon a more elaborate experiment, involving a realistic complete approach manoeuvre. Besides, a significant part of the paper focuses also on the experiment setup and the simulator equipment used, in order to put the results in the right perspective.

In section II, the used aircraft model is introduced. This section shows that a high fidelity simulation model has been used in this research, including failure modes of which some have been validated on flight data obtained from digital flight data recorders. Subsequently, the manual fault tolerant flight control method which has been tested for its post-failure handling qualities and workload is elaborated in section III. Thereafter, the experiment setup and evaluation procedure are discussed in section IV. Section V focuses on the observations and the analysis of the simulation results, concerning handling qualities and pilot workload, more precisely physical as well as compensatory workload. Finally, concluding remarks are presented.

\section{Aircraft model}

The present work is part of a research project by the Group for Aeronautical Research and Technology in Europe (GARTEUR). This group has established flight mechanics action group FM-AG(16) with the specific goal to investigate the possibilities of fault tolerant control in aeronautics and to compare the results of different reconfiguring control strategies applied to a reference benchmark flight trajectory. That benchmark scenario is inspired by the Bijlmermeer disaster of EL AL flight 1862, where a Boeing 747-200 Cargo aircraft of Israel's national airline EL AL lost two engines immediately after take-off from Amsterdam airport Schiphol in the Netherlands and crashed into an apartment building in the neighborhood while trying to return to the airport. A detailed simulation model of this damaged aircraft is available from the NLR. This RECOVER (REconfigurable COntrol for Vehicle Emergency Relief) benchmark model is discussed in detail 
in the literature 2,20 and has been used (also in earlier versions) by a number of investigators and organizations. $^{21-23}$ More information about the reference benchmark scenario can be found in the literature. ${ }^{24,25}$ Other control strategies and results as part of the framework of FM-AG(16) have been applied to the same benchmark model. ${ }^{13,26-29}$ This holds also for related FDI work. ${ }^{30,31}$ A book about the work and results of GARTEUR FM-AG(16) is in preparation for publication in the Lecture Notes in Control and Information Sciences series by Springer-Verlag. ${ }^{32}$

The simulation benchmark for evaluating fault tolerant flight controllers ${ }^{2}$ contains six benchmark fault scenarios, enumerated in fig. 1(a). These failure cases have varying criticality. Fig. 1(b) shows the failure modes and structural damage configuration of the Flight 1862 accident aircraft, which is the most important fault scenario in the simulation benchmark.

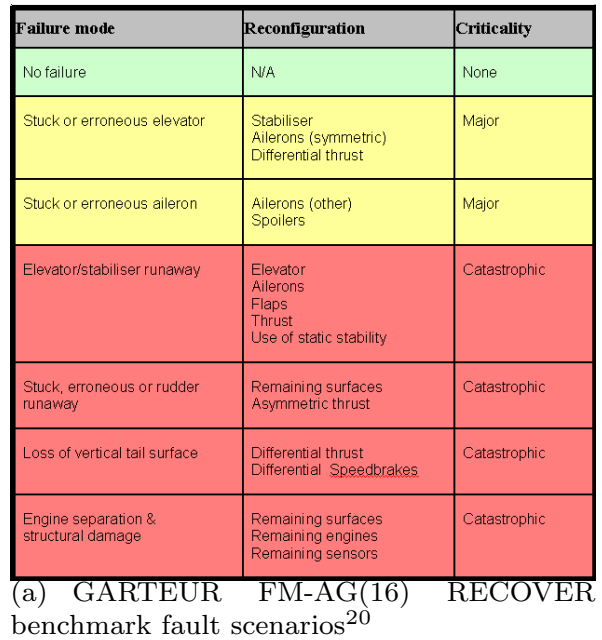

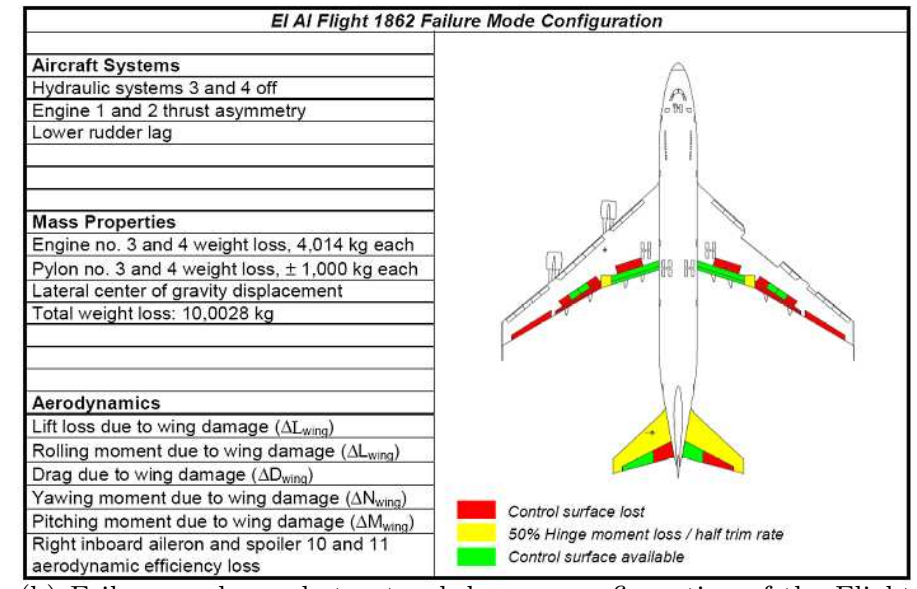

(b) Failure modes and structural damage configuration of the Flight 1862 accident aircraft, suffering right wing engine separation, partial loss of hydraulics and change in aerodynamics ${ }^{20}$

Figure 1. GARTEUR FM-AG(16) RECOVER benchmark fault scenarios and configuration

The stabilizer and rudder runaway and the EL AL engine separation have been used as scenarios for this paper. In the case of a stabilizer or rudder runaway (also called hardover), the stabilizer or rudder moves quickly to an extreme position. In case of stabilizer runaway, the horizontal stabilizer suffers a leading edge upward shift of 2 degrees, resulting in a diving effect of the aircraft. In the rudder hardover scenario, the rudder deflects to the left, inducing a yawing tendency of the aircraft to the left. The rudder deflection limit in this scenario depends on the flight speed, because aerodynamic blowdown is taken into account in the RECOVER simulation model. As a result the maximum rudder deflection is slightly below $15^{\circ}$ for an airspeed around $270 \mathrm{knots}$, and even close to $25^{\circ}$ (the physical maximum deflection limit imposed by the rudder control system structure) for an airspeed of 165 knots. The El Al engine separation scenario is an accurate digital flight data recorder (DFDR) data validated simulation of flight 1862, as explained previously, where the loss of hydraulics is taken into account.

\section{Fault Tolerant Control method}

This controller combines real time physical model identification with adaptive nonlinear dynamic inversion (ANDI). The aircraft model, including any failures, is continuously monitored with a two-step method (TSM), consisting of an aircraft state estimation step (ASE), followed by an aerodynamic model identification step (AMI). In this second step, an a-priori aerodynamic model is updated to match the actual post-failure aircraft dynamics as soon as a failure occurs. The resulting model is supplied to the adaptive nonlinear dynamic inversion routine, which transforms the dynamics of the aircraft (as controlled by the pilot) to a rate control system. This adaptive dynamic inversion routine consists of two loops. The inner loop is a body angular rate control loop, discussed in section 1. An outer loop is added in order to give the pilot the possibility to control sideslip angle by means of the pedals, as explained in section 2. All modules are briefly elaborated 
below. More detailed information about the ANDI control system design is available in the literature. ${ }^{33}$

\section{A. Identification: two step method}

The identification method considered in this study is the two step method (TSM), which has been continuously under development at Delft University of Technology over the last 20 years. ${ }^{34-37}$ There are many other identification algorithms mentioned in the literature such as maximum likelihood identification (MLI) and other one step identification routines, but not all of them are applicable to real time embedded computation. One of the few procedures which can be implemented in real time is the filtering method developed at the German Aerospace Research Center DLR. ${ }^{38}$ This is a joint state and parameter estimation algorithm, but very complex. Another algorithm works also in real-time and is frequency based. ${ }^{39}$ In this context, one is looking for real-time physical parameter estimates in nonlinear models. Therefore, the two step method seems to be the most appropriate and direct. One of the major advantages of the two step method, is the decomposition of a global non-linear one step identification method in two separate steps, ${ }^{40}$ where the nonlinear part is isolated in the aircraft state estimation (ASE) step. The use of a Kalman filter in the first step makes it fairly straightforward to merge redundant but contaminated data, resulting in even higher accuracies. Consequently, the aerodynamic model parameter identification procedure in the second step can be simplified to a linear procedure. The aim is to update an a priori aerodynamic model (obtained by means of windtunnel tests and CFD calculations) by means of on-line flight data. The first step is called the Aircraft State Estimation (ASE) phase, where the second one is the Aerodynamic Model Identification (AMI) step. In the Aircraft State Estimation procedure, an Iterated Extended Kalman Filter (IEKF) is used to determine the aircraft states, the measurement equipment properties (sensor biases) and the wind components, by making use of the nonlinear kinematic and observation models, based upon redundant but contaminated information from all sensors (air data, inertial, magnetic and GPS measurements). By means of this state information, the input signals of the pilot and the earlier measurements, it is possible to construct the combined aerodynamic and thrust forces and moments acting on the aircraft, and by means of a recursive least squares (RLS) operation, finally the aerodynamic derivatives can be deduced.

\section{B. Control: ANDI}

For the reconfigurable control algorithm, a model based control method needs to be chosen. One of the valid approaches is the concept of adaptive nonlinear dynamic inversion (NDI). Nonlinear dynamic inversion has been used before in the literature for flight control and aircraft guidance, ${ }^{41-43}$ where one of its main advantages is the absence of any need of gain scheduling over the flight envelope. Enhanced NDI strategies have been applied for reconfigurable flight control in the case of stuck or missing effectors. ${ }^{44}$ However, this reference mentions the need for relatively noise free critical measurements and uses only one NDI loop with a position/angle allocator. The application discussed in this section however, can deal with noisy measurements thanks to the presence of a robust identification routine acting on the measurements. Moreover, a dual NDI loop has been implemented here, with inner loop body angular rate and outer loop sideslip angle tracking properties. This overall combination greatly increases the ability to reconfigure the aircraft in the presence of component as well as structural failures.

\section{Rate control inner loop}

The idea of nonlinear dynamic inversion is first to transform the original $\mathrm{n}$-th order nonlinear system $\mathbf{x}^{(n)}=$ $\mathbf{a}(\mathbf{x})+\mathbf{b}(\mathbf{x}) \mathbf{u}$ into a companion form and then to solve for the physical control input $\mathbf{u}$ by introducing an outer loop control input $\boldsymbol{\nu}$. By making use of Nonlinear Dynamic Inversion (NDI), the nonlinear aircraft dynamics can be canceled out such that the resulting system behaves like a pure single integrator. For this, the physical control input $\mathbf{u}$ is defined as follows:

$$
\mathbf{u}=\mathbf{b}^{-1}(\mathbf{x})(\boldsymbol{\nu}-\mathbf{a}(\mathbf{x}))
$$

where $\boldsymbol{\nu}$ is the virtual outer loop control input. Furthermore, $\mathbf{a}(\mathbf{x})$ represents the airframe/engine model and $\mathbf{b}(\mathbf{x})$ is the effector blending model. Note that the effector blending model $\mathbf{b}(\mathbf{x})$ needs to be inverted. More information is available in the literature. ${ }^{35,45}$ 
A similar structure can be found for aircraft control applications:

$$
\begin{aligned}
& {\left[\begin{array}{l}
\delta_{a} \\
\delta_{e} \\
\delta_{r}
\end{array}\right]=\left[\begin{array}{ccc}
b \tilde{C}_{l_{\delta_{a}}} & 0 & b \tilde{C}_{l_{\delta_{r}}} \\
0 & \bar{c} \tilde{C}_{m_{\delta_{e}}} & 0 \\
b \tilde{C}_{n_{\delta_{a}}} & 0 & b \tilde{C}_{n_{\delta_{r}}}
\end{array}\right]^{-1}} \\
& \left\{\frac{\mathbf{I}}{\frac{1}{2} \rho V^{2} S}\left(\left[\begin{array}{c}
\nu_{p} \\
\nu_{q} \\
\nu_{r}
\end{array}\right]+\mathbf{I}^{-1}\left[\begin{array}{c}
p \\
q \\
r
\end{array}\right] \times\left(\mathbf{I}\left[\begin{array}{c}
p \\
q \\
r
\end{array}\right]\right)-\left[\begin{array}{c}
b C_{l_{\text {states }}} \\
\bar{c} C_{m_{\text {states }}} \\
b C_{n_{\text {states }}}
\end{array}\right]\right\}\right.
\end{aligned}
$$

where the virtual inputs $\left[\begin{array}{lll}\nu_{p} & \nu_{q} & \nu_{r}\end{array}\right]^{T}$ are the time derivatives of the rotational rates of the aircraft, which are selected to be the control variables in order to obtain rate control. The first part of (2) performs the control inversion, while the second part contains the state inversion. Moreover, control effectivity is defined as follows:

$$
\begin{aligned}
\tilde{C}_{l_{\delta_{a}}} & =-C_{l_{\delta_{a_{i r}}}}+C_{l_{\delta_{a_{i l}}}}-C_{l_{\delta_{a_{o r}}}}+C_{l_{\delta_{a_{o l}}}}-C_{l_{\delta_{s p_{1}}}}-\ldots-C_{l_{\delta_{s p_{5}}}}+C_{l_{\delta_{s p} p_{8}}}+\ldots+C_{l_{\delta_{s p_{12}}}} \\
\tilde{C}_{n_{\delta_{a}}} & =-C_{n_{\delta_{a_{i r}}}}+C_{n_{\delta_{a_{i l}}}}-C_{n_{\delta_{a_{o r}}}}+C_{n_{\delta_{a_{o l}}}}-C_{n_{\delta_{s p_{1}}}}-\ldots-C_{n_{\delta_{s p_{5}}}}+C_{n_{\delta_{s p_{8}}}}+\ldots+C_{n_{\delta_{s_{1}} p_{12}}} \\
\tilde{C}_{m_{\delta_{e}}} & =C_{m_{\delta_{e_{i r}}}}+C_{m_{\delta_{e_{i l}}}}+C_{m_{\delta_{e_{o r}}}}+C_{m_{\delta_{e_{o l}}}} \\
\tilde{C}_{l_{\delta_{r}}} & =C_{l_{\delta_{r_{u}}}}+C_{l_{\delta_{r_{l}}}} \\
\tilde{C}_{n_{\delta_{r}}} & =C_{n_{\delta_{r_{u}}}}+C_{n_{\delta_{\delta_{l}}}}
\end{aligned}
$$

The different aileron, elevator, rudder and spoiler surfaces are coupled and deflect in a fixed coordinated way, as illustrated by eq. (3) through (7). All four ailerons and ten spoilers deflect simultaneously. The same holds for the four elevator surfaces and the upper and lower rudder. The development of a more flexible control allocation algorithm is part of future work. Nevertheless, the results shown here prove that this simplification has no serious detrimental effect on the performance of the FTFC module.

The weakness of classical NDI, its sensitivity to modeling errors which leads to erroneous inversion, and thus a possibly unstable result, is circumvented here by making use of the real time identified physical model, which has a greater accuracy than an off-line model. As a result, one does not only obtain an adaptive NDI routine which renders the aircraft behavior like a pure integrator in nominal situations. In failure situations, the modified aircraft model is identified by the two step method and immediately applied in the model-based adaptive NDI routine, which allows reconfiguring for the failure in real time.

The inner loop thus focuses on pure body fixed angular rate control as elaborated in equation (2) and as illustrated in fig. 2. The distinction between the inner and outer loops has been based upon the time scale separation principle.

\section{Manual control outer loop}

For manual control, an outer loop is needed in order to convert the pilot pedals input into a sideslip $\beta$ command rather than a yaw rate $r$ command. A pure classical feedback loop works for unfailed aircraft, but this will not perform adequately for asymmetrically damaged aircraft, where a certain steady non-zero sideslip angle $\beta$ and/or roll angle $\phi$ is necessary to compensate for the asymmetry. Therefore, this loop must also be NDI-based, where the feedback path makes use of the lateral specific force $A_{y}$ (which is related to the sideslip angle), the roll angle $\phi$, and the commanded roll rate $p_{\text {comm }}$.

The control law can be deduced in the same way as for the inner loop described earlier, where a relation must be found between the sideslip angle $\beta$ and the body fixed angular rates:

$$
r=\left(\frac{-u}{\sqrt{V^{2}-v^{2}}}\right)^{-1} \cdot\left\{\nu_{\beta}-\frac{1}{\sqrt{V^{2}-v^{2}}}\left[A_{y}+g \cos \theta \sin \phi+w p_{\text {comm }}\right]\right\}
$$

The resulting manual control outer loop architecture is shown in Figure 3. In this set-up the pilot's controls work as follows. Control wheel steering supplies a reference roll rate, pitch rate tracks the control 


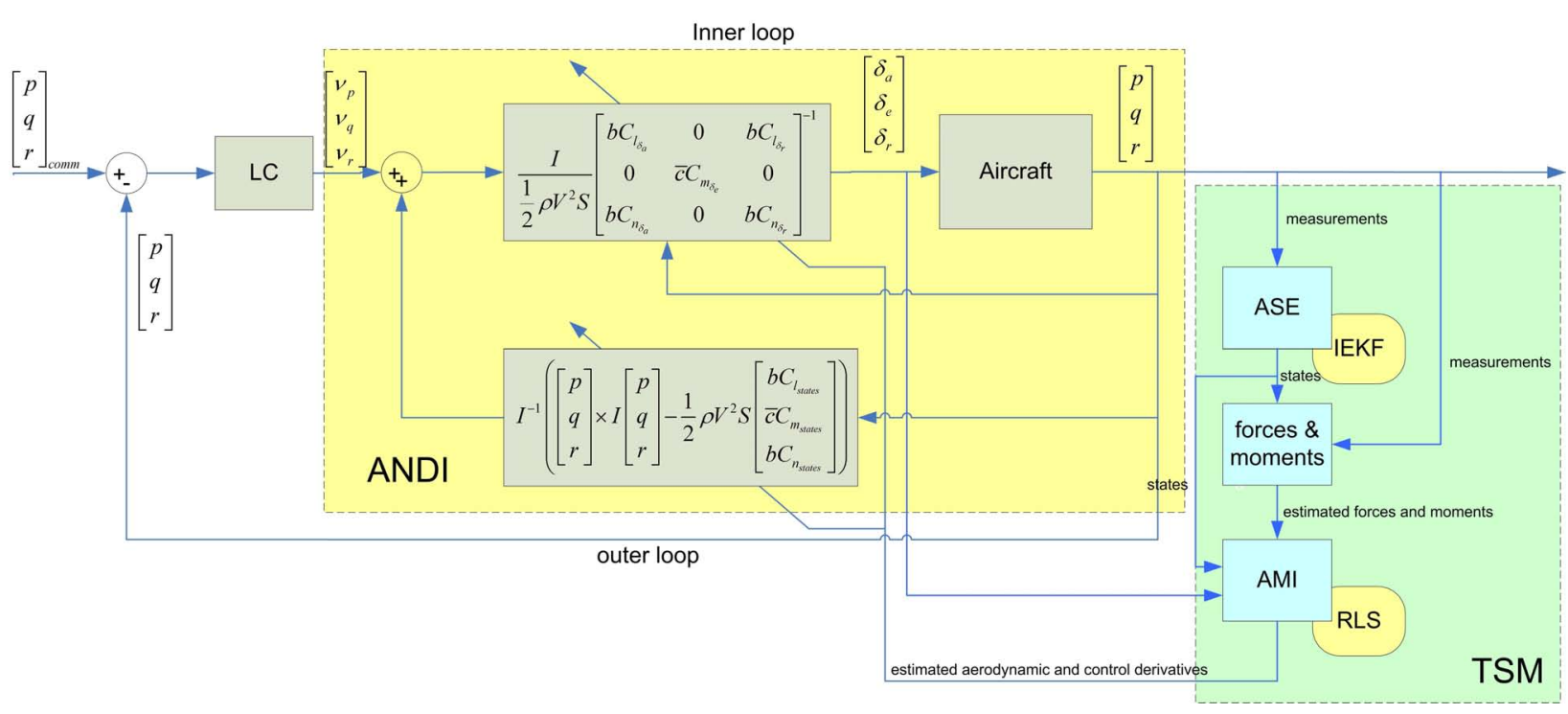

Figure 2. NDI rate control inner loop; ANDI = adaptive nonlinear dynamic inversion, TSM $=$ two step method, ASE = aircraft state estimation, IEKF = iterated extended Kalman filter, AMI = aerodynamic model identification, $\mathrm{RLS}=$ recursive least squares, $\mathrm{LC}=$ linear controller

column, and the pedals give the commanded sideslip angle, which is limited between $+5^{\circ}$ and $-5^{\circ}$. Moreover, to ensure satisfactory aircraft responses to the pilot inputs, some first order low pass filters have been added in the input channel. In the inner loop, the linear controllers involve proportional-integral control, and gains have been selected to ensure favorable handling qualities by means of damping ratio $\zeta$ and natural frequency $\omega_{n}$.

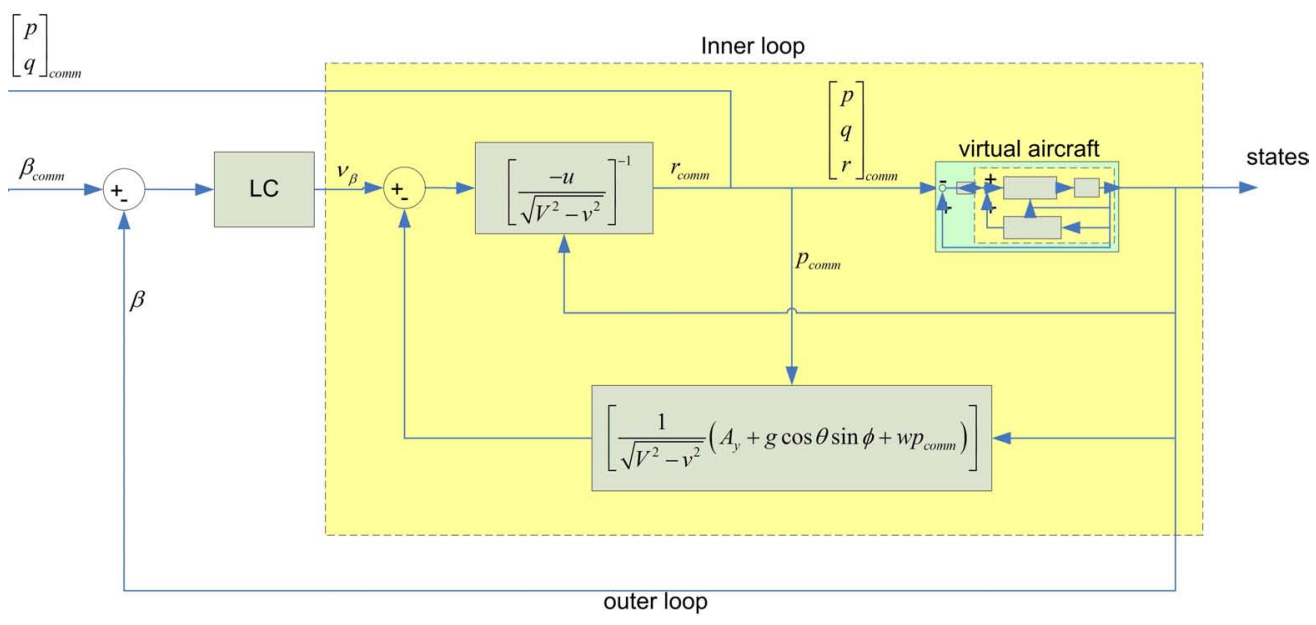

Figure 3. NDI manual control outer loop; LC $=$ linear controller

\section{Experiment method}

The method for the piloted evaluation was based on procedures for human factors experiments. Some procedures were shortened to remain within the available time frame. The number of pilots and repetitions were smaller than required for a full statistical analysis of the experiment, but are sufficient to observe certain trends. 


\section{A. Design}

The base-line condition for comparison was the conventional flight control system, which was manually flown. The controller considered in this paper is set up such that the pilot could manually maneuver the aircraft, much like the conventional manual control strategy. In this case, the perceived dynamics were modified by the fly-by-wire algorithm to a rate command/attitude hold scheme.

During the evaluation, the aircraft was flown in the manual classical (mechanical) flight control system mode and in FTFC mode. In the former configuration, aircraft control was achieved via the mechanical and hydraulic system architecture modeled after the real aircraft. In the latter configuration, all control surfaces were commanded via the FTFC module.

The failures were flown in a fixed order with half of the pilots first flying with classical control and the other half with the FTFC under investigation. At the start of the session the pilot was given some time to familiarize himself with the simulator, experiment procedure and rating scales in the classical control mode.

\section{B. Dependent measures}

The controller was assessed on two types of dependent measures: implementation and operational.

\section{Implementation}

One measure of a controller's practical applicability is the computational load on the Flight Control Computer. The amount of additional calculations necessary for fault-tolerant control must be sufficiently low to enable actual introduction within the foreseeable future.

The computational load was measured in the simulator software environment without a pilot in the loop. For comparison purposes a standard desktop PC (AMD Athlon ${ }^{\mathrm{TM}}$ X2 5600+ processor) was used to measure the time needed by the algorithm to perform a single integration step.

The simulation software was used to time the invocation of the controller's main function. This function included some overhead of getting the input data from other parts of the simulation and publishing the results, but this overhead was minimal (typically around $20 \mu \mathrm{s}$ ). This measurement can help in identifying the relative impact of the controller design on the computational load.

\section{Operational variables}

The operational variables were concerned with the interaction between the controller and pilot. Objective (for example, measured pilot control activity) and subjective (for example, handling qualities rating) operational variables were measured.

The objective measurements in the FM-AG-16 evaluation consisted of the pilot's control inputs and the states of the aircraft.

For the subjective measurement, the Cooper-Harper handling qualities rating scale was used. ${ }^{46}$ This rating scale is commonly used to provide a framework in assessing the handling qualities of a particular aircraft (or configuration) and the required workload and performance in a particular task. The performance of the reconfigured aircraft was assessed in a series of six flight phases, most of which were explicitly rated by the pilot. These flight phases were:

- Straight and level flight (not rated)

- Altitude changes

- Bank angle captures

- Right-hand turn (not rated)

- Localizer intercept

- Glideslope intercept

The wording on the scale is geared towards use during the development program of a new aircraft type. For an aircraft with structural or mechanical failures, it was sometimes tempting to take the degradations into account in the rating and not rate it as a fully functional aircraft ready to go into production. In such a 
case the pilot sometimes seemed to be willing to give a low (good) rating, even though the required workload and degraded performance would be totally unacceptable in daily operations. It was stressed however that the rating should be given to the aircraft "as is" without taking the mitigating circumstances of the failure into account. Only in this way a fair comparison can be made between the nominal aircraft and the failed aircraft, as well as between the classical and fault-tolerant control schemes.

To increase the validity of the rating, especially for inexperienced pilots, they were advised for every evaluation to explicitly follow the decision tree of the rating scale and correlate the attained performance with the experienced workload. Saving time by directly choosing a pilot rating number or not relating the rating with the actual performance would have seriously degraded the quality of the recorded ratings.

In the FM-AG-16 evaluation, a number of tasks and performance criteria were defined. In general the lateral and longitudinal handling qualities were given separate ratings. Also, in some cases the task direction would be influenced by the specific failure, so these were split up as well, e.g. right and left bank angle capture or up and down altitude captures. Table 1 summarizes the tasks that were to be rated, along with the adequate and required performance criteria.

The pilots were given feedback on their performance before filling in the rating scales, as described in section E.

\section{Participants}

Familiarity with the flown aircraft is one of the main requirements for the participants in a piloted evaluation. Some flight test or evaluation experience is also beneficial, especially when using standard rating scales.

In this campaign five professional airline pilots with an average experience of about 15.000 flight hours, participated in the evaluation. They were all type rated for the Boeing 747 aircraft, and had experience in HQ evaluations and the rating method used.

\section{Apparatus}

The FM-AG-16 evaluation was performed on the SIMONA Research Simulator (SRS, Figure 4) at Delft University of Technology. The SRS is a 6-DOF research flight simulator, with configurable flight deck instrumentation systems, wide-view outside visual display system, hydraulic control loading and motion system. The middleware software layer called DUECA (Delft University Environment for Communication and Activation) allows rapid-access for programming of the SRS, relieving the user of taking care of the complexities of network communication, synchronization, and real-time scheduling of the different simulation modules. ${ }^{47}$

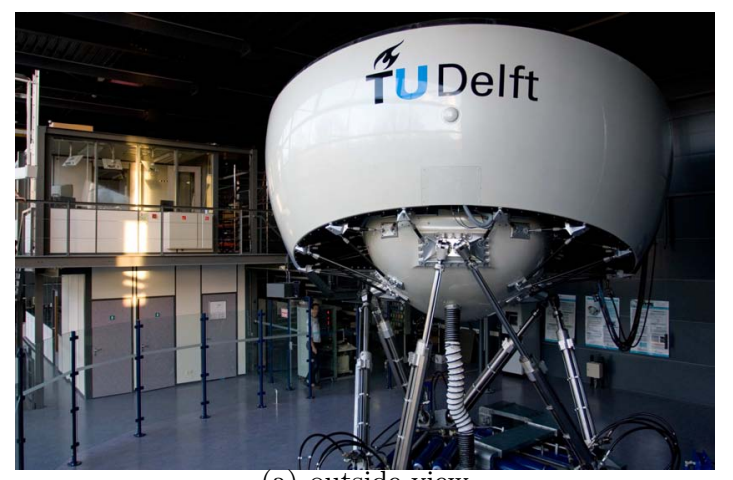

(a) outside view

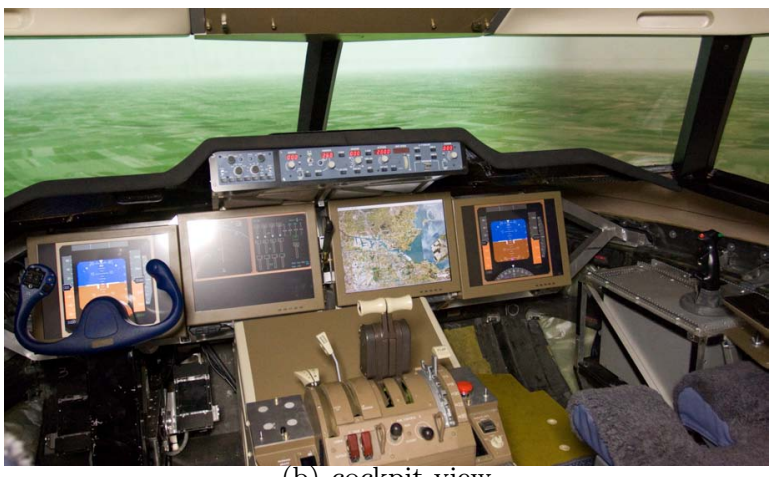

(b) cockpit view

Figure 4. The SIMONA (SImulation, MOtion and NAvigation) Research Simulator (SRS) at Delft University of Technology, source: Joost Ellerbroek 


\begin{tabular}{|c|c|c|c|}
\hline Maneuver & Description & Lateral performance & Longitudinal performance \\
\hline $\begin{array}{l}\text { Altitude cap- } \\
\text { ture }\end{array}$ & $\begin{array}{l}\text { Intercept the new altitude } \\
\text { with a climb or sink rate of } \\
\text { at least } 1000 \text { feet/minute and } \\
\text { without over- or undershoots } \\
\text { outside of the required perfor- } \\
\text { mance band. Maintain head- } \\
\text { ing and airspeed within the } \\
\text { required performance bands. }\end{array}$ & $\begin{array}{l}\text { Required: } \\
\quad \text { - heading: } \pm 2^{\circ} \\
\text { Adequate: } \\
\text { - heading: } \pm 4^{\circ}\end{array}$ & $\begin{array}{l}\text { Required: } \\
\text { - altitude: } \pm 50 \text { feet } \\
\text { - speed: } \pm 5 \text { knots } \\
\text { Adequate: } \\
\text { - altitude: } \pm 100 \text { feet } \\
\text { - speed: } \pm 10 \text { knots }\end{array}$ \\
\hline $\begin{array}{l}\text { Bank angle cap- } \\
\text { ture }\end{array}$ & $\begin{array}{l}\text { Attain a } 20 \text { degree bank an- } \\
\text { gle as quickly and precisely } \\
\text { as possible and hold it sta- } \\
\text { ble. Maintain altitude and } \\
\text { airspeed within the required } \\
\text { performance bands. }\end{array}$ & $\begin{array}{l}\text { Required: } \\
\text { - bank: } 20 \pm 1^{\circ} \\
\text { Adequate: } \\
\text { - bank: } 20 \pm 2^{\circ}\end{array}$ & $\begin{array}{l}\text { Required: } \\
\text { - altitude: } \pm 50 \text { feet } \\
\text { - speed: } \pm 5 \text { knots } \\
\text { Adequate: } \\
\text { - altitude: } \pm 100 \text { feet } \\
\text { - speed: } \pm 10 \text { knots }\end{array}$ \\
\hline $\begin{array}{l}\text { Localizer inter- } \\
\text { cept }\end{array}$ & $\begin{array}{l}\text { Intercept and follow the local- } \\
\text { izer. Maintain altitude and } \\
\text { airspeed within the required } \\
\text { performance bands. }\end{array}$ & $\begin{array}{l}\text { Required: } \\
\text { - offset: } \pm 0.5 \mathrm{dot} \\
\text { Adequate: } \\
\text { - offset: } \pm 1 \mathrm{dot}\end{array}$ & $\begin{array}{l}\text { Required: } \\
\text { - altitude: } \pm 50 \text { feet } \\
\text { - speed: } \pm 5 \text { knots } \\
\text { Adequate: } \\
\text { - altitude: } \pm 100 \text { feet } \\
\text { - speed: } \pm 10 \text { knots }\end{array}$ \\
\hline $\begin{array}{l}\text { Glideslope } \\
\text { intercept }\end{array}$ & $\begin{array}{l}\text { Intercept and follow the glide } \\
\text { slope and localizer. Main- } \\
\text { tain airspeed with the re- } \\
\text { quired performance band. }\end{array}$ & $\begin{array}{l}\text { Required: } \\
\text { - localizer offset: } \pm \\
0.5 \text { dot } \\
\text { Adequate: } \\
\text { - localizer offset: } \pm 1 \\
\quad \text { dot }\end{array}$ & $\begin{array}{l}\text { Required: } \\
\text { - glideslope offset: } \pm \\
0.5 \text { dot } \\
\text { - speed: } \pm 5 \text { knots } \\
\text { Adequate: } \\
\text { - glideslope offset: } \pm \\
1 \text { dot } \\
\text { - speed: } \pm 10 \text { knots }\end{array}$ \\
\hline
\end{tabular}

Table 1. Performance criteria divided by maneuver type

10 of 25 


\section{Flight deck instrumentation}

The flight deck of the SRS was set up to resemble a generic, 2 person cockpit as found in many modern airliners. The installed hardware consisted of two aircraft seats, a conventional control column and wheel with hydraulically powered control loaders (captain's position) and rudder pedals, and an electrically actuated sidestick (1st officer's position, not used in this experiment), a B777 control pedestal, 4 LCD screens to display the flight instruments $(60 \mathrm{~Hz}$ refresh rate), and a B737 mode control panel (MCP).

The displays were based on the B747-400 Electronic Flight Instrumentation System (EFIS, see Figure 5). They were shown on the LCD panels mounted in front of the pilot at the ergonomically correct locations. Although not all display functionality was incorporated, the pilot had all the information available to fly the given trajectory. One notable omission was the Flight Director (FD), which normally gives steering commands to the pilot. Especially during the localizer and glide slope capture and tracking, the use of "raw ILS data" instead of the FD added somewhat to the pilot workload. To help the pilots assess the controller's actions, the surface deflections of the elevators (left/right), ailerons (left/right, inner/outer) and rudders (upper/lower) were shown in the upper right hand corner of the Engine Indication and Crew Alerting System Display (EICAS).

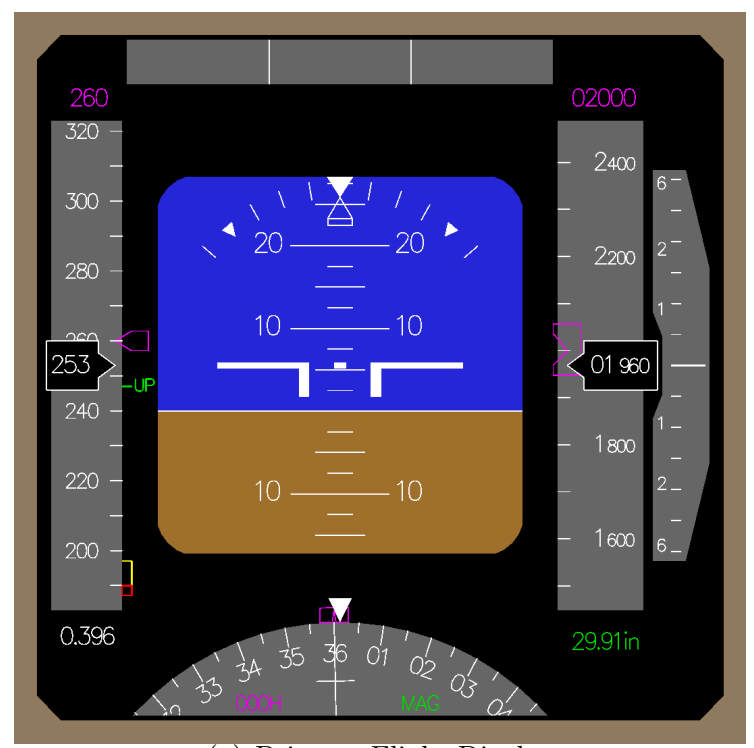

(a) Primary Flight Display

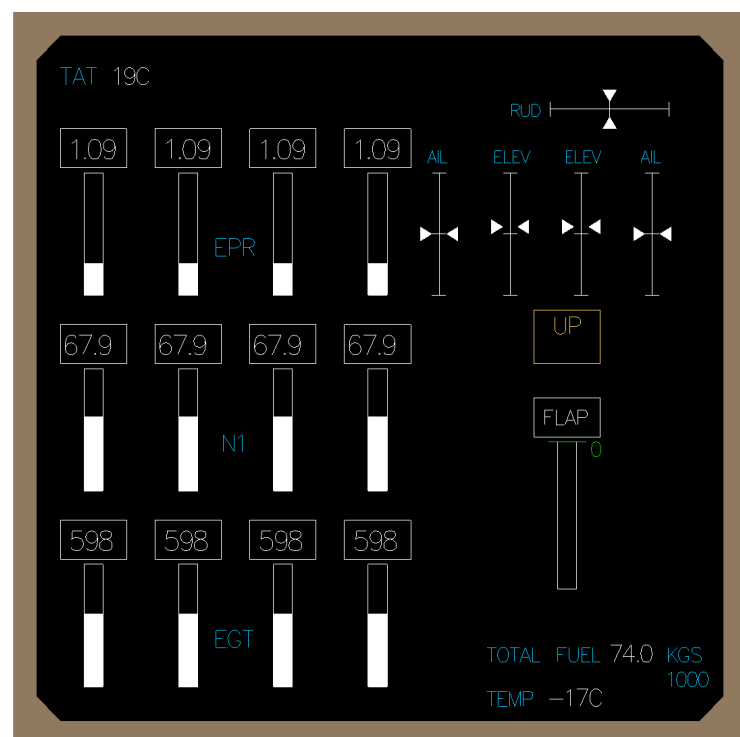

(b) Engine Indication and Crew Alerting System Display. AIL, ELEV and RUD on the EICAS indicate aileron, elevator and rudder deflections respectively.

Figure 5. The PFD and EICAS flight deck displays presented to the pilot during the simulation runs

\section{Outside visual system}

The SRS has a wide field-of-view collimated outside visual system to give the pilot attitude information, as well as to induce a sense of motion through the virtual world. Three LCD projectors produce computer generated images on a rear-projection screen, which was viewed by the pilots through the collimating mirror. The resulting visual has a field of view of $180 \times 40$, with a resolution of $1280 \times 1024$ pixels per projector. Update rate of the visual was the same as the main simulation at $100 \mathrm{~Hz}$, while the projector refresh rate was $60 \mathrm{~Hz}^{48}$

For this evaluation, a visual representation of Amsterdam Airport Schiphol was used. All runways and major taxiways were in their correct location, complemented with the most important buildings on the airfield. The surrounding area was kept simpler, with a textured ground plane showing a rough outline of the Dutch coast and North Sea. 


\section{Control loading feel system}

The pilot used a conventional control column and wheel with hydraulically powered control loaders. The simulated dynamics of the controls were a constant mass-spring-damper system with parameters representative of the aircraft in the evaluated condition. The simulation model did not allow for feedback of surface forces to the controls, a feature that normally would have been present in a B747 aircraft (through the aircraft's q-feel system). This absence of surface deflection feedback forces may have reduced pilot control efficiency, especially in the mechanical failure cases.

\begin{tabular}{lll}
\hline \hline & pitch & roll \\
\hline \hline arm & $0.714 \mathrm{~m}$ & $0.17 \mathrm{~m}$ \\
spring constant & $474 \mathrm{Nm} / \mathrm{rad}$ & $5.416 \mathrm{Nm} / \mathrm{rad}$ \\
inertia & $5.577 \mathrm{Nms}^{2} / \mathrm{rad}$ & $0.478 \mathrm{Nms} / \mathrm{rad}$ \\
damping & $195.3 \mathrm{Nms} / \mathrm{rad}$ & $1.116 \mathrm{Nms} / \mathrm{rad}$ \\
break-out & $11.1 \mathrm{Nm}$ & $0.1313 \mathrm{Nm}$ \\
stiction/friction & $11.1 \mathrm{Nm}$ & $0.1313 \mathrm{Nm}$ \\
\hline \hline
\end{tabular}

Table 2. Control loading feel system characteristics

\section{Motion system}

The motion system of the SRS is a hydraulic hexapod with six degrees of freedom. Its cueing algorithm or washout filters can be easily adjusted to fit new aircraft dynamics or maneuvers. For this evaluation the severity of the motion was tuned down somewhat to allow for the sometimes violent maneuvers of the failures without reaching the limits of the motion base.

The cueing algorithm was of the classical washout design, with high-pass filters on all degrees of freedom and a tilt coordination channel to simulate low frequency surge and sway cues by tilting the simulator. The sway tilt was especially apparent in some failure cases where large sideslip angles and sideforces were persistently present.

\begin{tabular}{llllllll}
\hline \hline DOF & \multicolumn{2}{c}{ Kinematics } & \multicolumn{5}{c}{ Motion cueing algorithm } \\
\hline & $\begin{array}{l}\text { minimum } \\
\text { deflection }\end{array}$ & $\begin{array}{l}\text { maximum } \\
\text { deflection }\end{array}$ & gain & $\begin{array}{l}\text { high- } \\
\text { pass } \\
\text { filter } \\
\text { order }\end{array}$ & $\begin{array}{l}\text { high-pass } \\
\text { break } \\
\text { frequency }\end{array}$ & $\begin{array}{l}\text { low-pass } \\
\text { break } \\
\text { frequency }\end{array}$ & damping \\
& & & & & & \\
\hline \hline surge & $-0.981 m$ & $1.259 m$ & 0.5 & 2 & $2.0 \mathrm{rad} / \mathrm{s}$ & $4.0 \mathrm{rad} / \mathrm{s}$ & 1.0 \\
sway & $-1.031 \mathrm{~m}$ & $1.031 \mathrm{~m}$ & 0.5 & 2 & $2.0 \mathrm{rad} / \mathrm{s}$ & $4.0 \mathrm{rad} / \mathrm{s}$ & 1.0 \\
heave & -0.363 & $0.678 m$ & 0.4 & 3 & $2.0 \mathrm{rad} / \mathrm{s}$ & - & 1.0 \\
roll & $-25.9^{\circ}$ & $25.9^{\circ}$ & 0.5 & 1 & $2.0 \mathrm{rad} / \mathrm{s}$ & - & - \\
pitch & $-23.7^{\circ}$ & $24.3^{\circ}$ & 0.5 & 1 & $2.0 \mathrm{rad} / \mathrm{s}$ & - & - \\
yaw & $-41.6^{\circ}$ & $41.6^{\circ}$ & 0.5 & 1 & $1.0 \mathrm{rad} / \mathrm{s}$ & - & - \\
\hline \hline
\end{tabular}

Table 3. SRS motion system ${ }^{48}$

\section{E. Procedure}

The geometry of the SIMONA flight scenario (Figure 6) was based on the 1992 Amsterdam Bijlmermeer aircraft accident profile. ${ }^{49,50}$ The scenario consisted of a number of phases. First, a short section of normal flight, during which the controller should stabilize the aircraft, identify and correct for any deviations from the nominal trimmed aircraft condition, and give the pilot a sense of its non-failed handling qualities.

After the normal flight phase, which included a 90 degree right turn and acceleration from 260 to 270 knots, the simulator operator introduced the failure. For evaluation purposes, the pilot (but not the control system) 


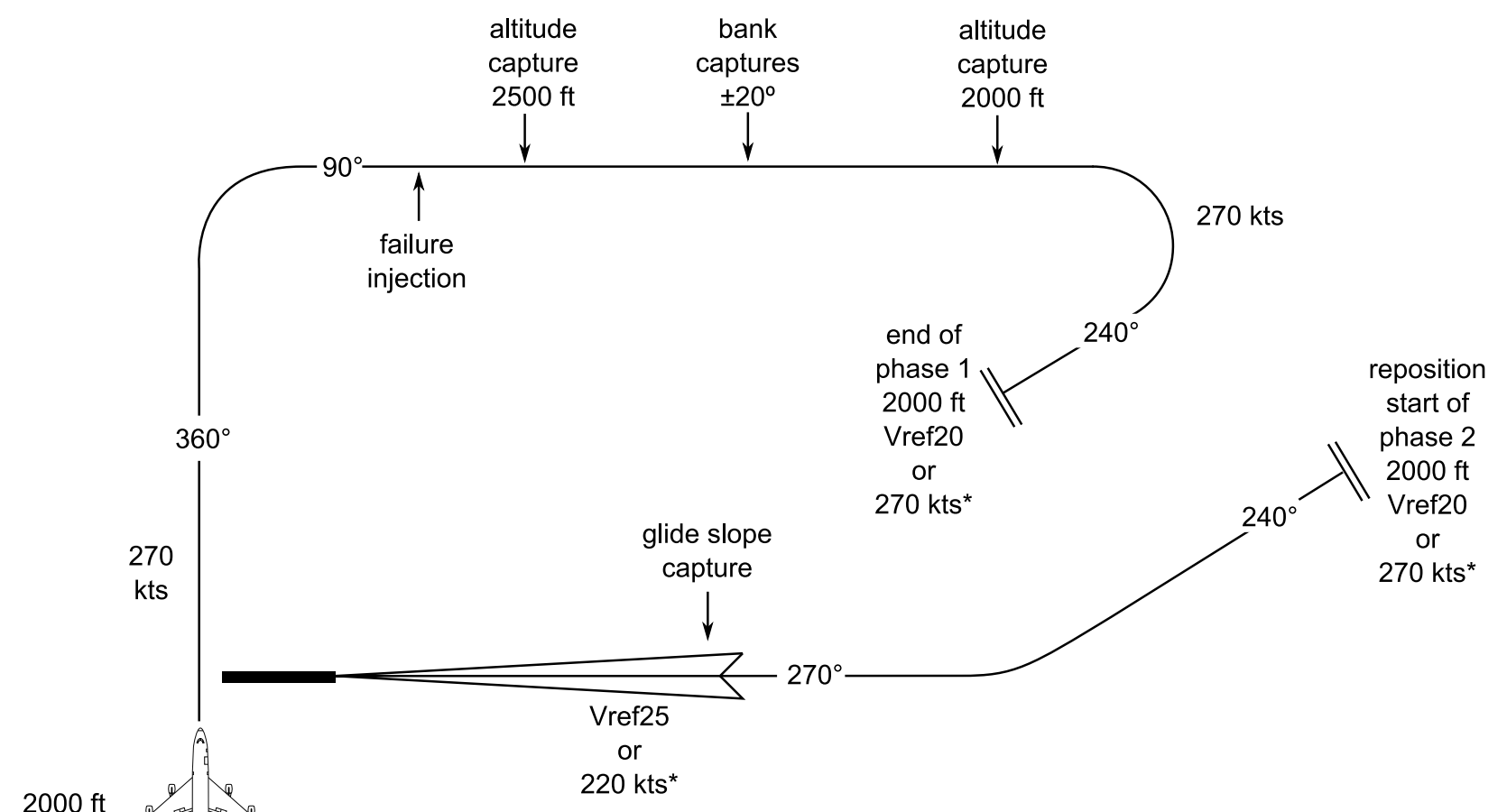

${ }^{*}$ High speed for engine separation failure

Figure 6. The definition of the experiment scenario as it was flown in the flight simulator

was informed of the type of failure and the moment of its occurrence. This decision reflects the desire to examine the post-failure handling qualities and not the initial reaction to the failure and (in the manual control case) the pilot's surprise and fault identification behavior. Initial tests of the fault-tolerant controller showed virtually no additional pilot action or compensation being required during and immediately after the failure, in stark contrast to the classical control configuration. Here the pilot spent considerable effort in recovering from the initial upset and developing a new control strategy to cope with the failure. By informing the pilot and thereby partly removing these tasks in the final evaluation, the pilot could better observe the failure and recovery and focus on the relative handling qualities in the post-failure configuration. It was felt this led to a fairer comparison between the classical and augmented configurations with less bias towards the latter.

The time span after the failure where control was recovered and the aircraft was brought back to a stable state, was called the recovery phase. In this phase the pilot could try different strategies to bring the aircraft back under control using manual control. If an FTFC algorithm was active, it could identify the problem and reconfigure itself to the new situation.

If this recovery was successful, the aircraft should again be in a stable flight condition. After recovery, an optional identification phase was introduced during which the flying capabilities of the aircraft could be assessed. This allowed for a complete parameter identification of the model for the faulty aircraft. The knowledge gained during this identification phase could be used by the controller to improve the chances of a safe and survivable landing. For the controller evaluated, no explicit identification phase was necessary, because the controller identified and reconfigured the aircraft and flight control system during the initial recovery and, if needed, continuously during later phases. In principle, the flight control systems was fully reconfigured to allow safe flight after the identification phase.

During the straight and level flight, the pilot could assess the workload necessary to maintain the aircraft in a stable condition. Once stable at 2000ft, the pilot was asked to make a rapid and precise altitude capture to $2500 \mathrm{ft}$. During the climb, airspeed and heading had to be kept constant. This maneuver was meant to 
examine the longitudinal handling qualities of the new aircraft configuration. At the new altitude the pilot was asked to perform bank angle captures of 20 degrees to the left and right. Again the goal was to make these captures as rapid and precise as possible, while maintaining altitude and speed. Banking the aircraft in this way was expected to expose undesirable lateral handling qualities.

After the bank angle captures, a new altitude capture was executed to bring the airplane back to $2000 \mathrm{ft}$. Speed and heading were maintained during the descent. Finally, a right hand turn towards 240 degrees was performed which brought the aircraft on an intercept heading to the ILS localizer of runway 27 at Amsterdam Airport Schiphol (AMS). For all failures, except the El Al Flight 1862 failure, the pilot was asked to decelerate to $174 \mathrm{kts}$, which was Vref20 a for this configuration. Once stable on the new heading and airspeed, the simulator was paused to give the pilot the opportunity to fill in the rating scales.

To assist in providing Cooper-Harper ratings, the pilot was presented with time histories of the relevant parameters, along with their adequate and desired performance boundaries as defined in Table 1.

To maintain a constant approach geometry between runs, the aircraft was then repositioned at a point before the localizer intercept. To allow for some time for restabilization after the simulator "unfreeze", a point $5 \mathrm{NM}$ along track from the intercept point was used. This intercept point was also moved back 5 NM from the standard intercept point to allow for more time to capture the localizer. Especially for the El $\mathrm{Al}$ Flight 1862 failure case this was helpful because the intercept was performed with abnormally high speeds (270kts as opposed to $174 \mathrm{kts})$.

To capture the localizer, the pilot used raw ILS data on his display. The localizer was captured at an altitude of $2000 \mathrm{ft}$ with an airspeed of $174 \mathrm{kts}$ for all scenarios except the El Al Flight 1862 which used the higher speed of 270kts. After some time on the localizer, the aircraft intercepted the glide slope and the pilot started to descend. During the deceleration and glideslope capture, the normal configuration changes of flaps and landing gear were executed, except in the El Al Flight 1862 case. For this scenario, the aircraft model was identified only for the configuration with flaps 1 and gear up. It was not known how the aircraft would have reacted to other configurations and the validity of the model with those configurations was also unknown, so these were not used for the evaluation.

At an altitude of $500 \mathrm{ft}$ the run was stopped and the pilot filled in the rating scales for the second part of the flight.

The landing itself was not part of the benchmark, because a realistic aerodynamic model of the damaged aircraft in ground effect and gear down was not available. However, it was assumed that if the aircraft was brought to the threshold in a stable condition and within the runway boundaries, the pilot would likely have been able to perform the final flare and landing as well.

${ }^{a}$ Reference speed for flaps set at 20 degrees 


\section{Results}

In this section, handling qualities and workload results are given on the manually flown Real-Time Model Identification and Nonlinear Dynamic Inversion Controller.

\section{A. FTC and pilot performance analysis results: time histories}

The adaptive NDI control system has been validated on three failure scenarios besides the unfailed flight. The flown damaged scenarios have been selected in the simulation model's failure mode library, based upon relevance and practical value. The engine separation failure and the rudder runaway scenarios have been inspired by realistic accidents which have happened before. The stabilizer runaway is another example of practical value and of interest for civil airliner manufacturers. Considering the restricted available time, the evaluation phase has concentrated on these three scenarios.

Figure 7(a) shows the pilot control deflections for the unfailed situation. This figure shows that there is no significant difference in required control deflections between both control alternatives in unfailed conditions, but this graph serves as a benchmark for the subsequent analysis for the different failure cases. Figure 7(b) shows that no sustained pitch deflection is necessary to compensate for the failure in the FTFC case, in contrast to the classic control case, which occurs at approximately at $t=150$ s. No significant differences are visible in the roll and yaw channel, because the failure has only consequences for the longitudinal controls. In fact, this behavior can also be called 'autotrim', because all unrequested pitch rates are automatically canceled out. During the simulation run, the pilot stated that there was no noticeable difference between the FTFC controlled aircraft suffering stabilizer runaway and an unfailed aircraft.

In the engine separation scenario, the failure is much more demanding for the pilot. However, this is dependent upon the speed regime where he is flying. The failure dynamics only become apparent for lower airspeeds.

The rudder runaway is the most challenging failure from the pilot perspective. Figure 7(c) and 7(d) show that the pilot has to use all available steering channels (roll by the steering wheel, pitch by the column and yaw by the pedals) to keep the aircraft under control in the case of classical control. The failure occurs around $\mathrm{t}=200 \mathrm{~s}$ in both cases. Comparing classical and fault tolerant control shows that a fault tolerant flight controller requires no more control effort from the pilot on these steering channels than before the failure. The pedals for instance, need no pilot input at all to minimize the sideslip of the aircraft in the case of FTFC. At the end of the scenario a small pedal input is made prior to touchdown to line the aircraft up with the runway. Only at the very end of fig. 7(c) is a much larger pilot input seen in the FTFC data. This was caused by the pilot making a corrective action to avoid exceeding the safe flight envelope boundary in the final approach because of a low approach speed. More information about this will be given later, see also fig. 9 .

This event highlights how information about the remaining pilot authority and the restricted safe flight envelope would contribute significantly to the pilot's awareness. It should also be noted that, to ensure sufficient lateral controllability in the rudder runaway scenario, differential thrust must be applied. Finally, some comments are given concerning the time scale. No timing requirements have been given to the pilot, resulting in some variations in time scales, depending on failure and control system. The oscillatory behavior at the end of the maneuver corresponds to the pilot inputs in order to line up the aircraft with the runway at the end of the final approach phase.

Fig. 8 and 9 show the time histories of a selection of the most important aircraft states. These confirm the evaluation trajectory as outlined in fig. 6. Moreover, altitude and roll angle plots illustrate the altitude and roll angle captures executed by the test pilot to evaluate the post-failure handling qualities of the aircraft. Fig. 9 gives some additional information about the situation where the safe flight envelope boundary has been exceeded. The velocity graph shows that airspeed in the fault tolerant control case is allowed to reduce significantly lower than for the classical control case. At some point, the minimum controllable airspeed is exceeded, slightly above $100 \mathrm{~m} / \mathrm{s}$, and the aircraft exhibits a rolling tendency to the right which is almost impossible to counteract. Opening throttles for increasing airspeed even aggravates this behavior, since only the left hand engines are providing thrust. After some major effort, the test pilot succeeds to stabilize the 

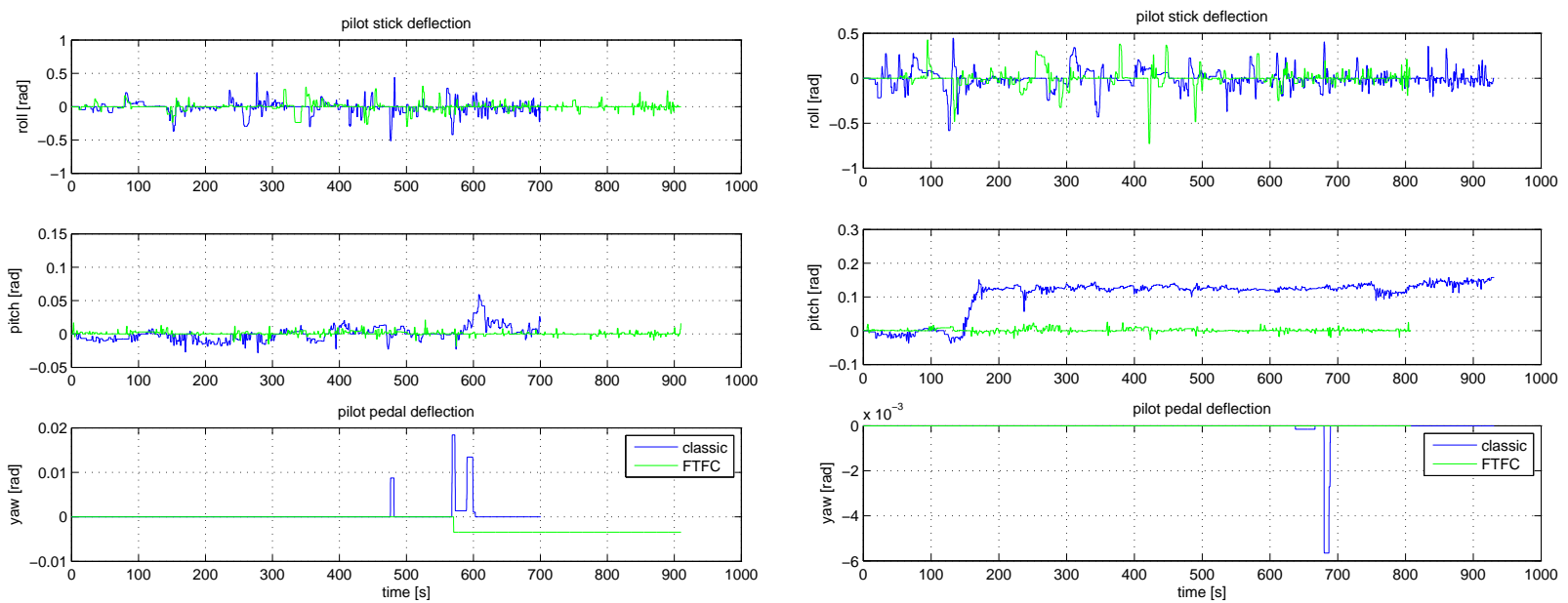

(a) unfailed

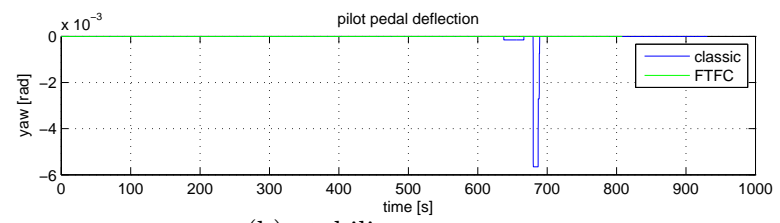

(b) stabilizer runaway
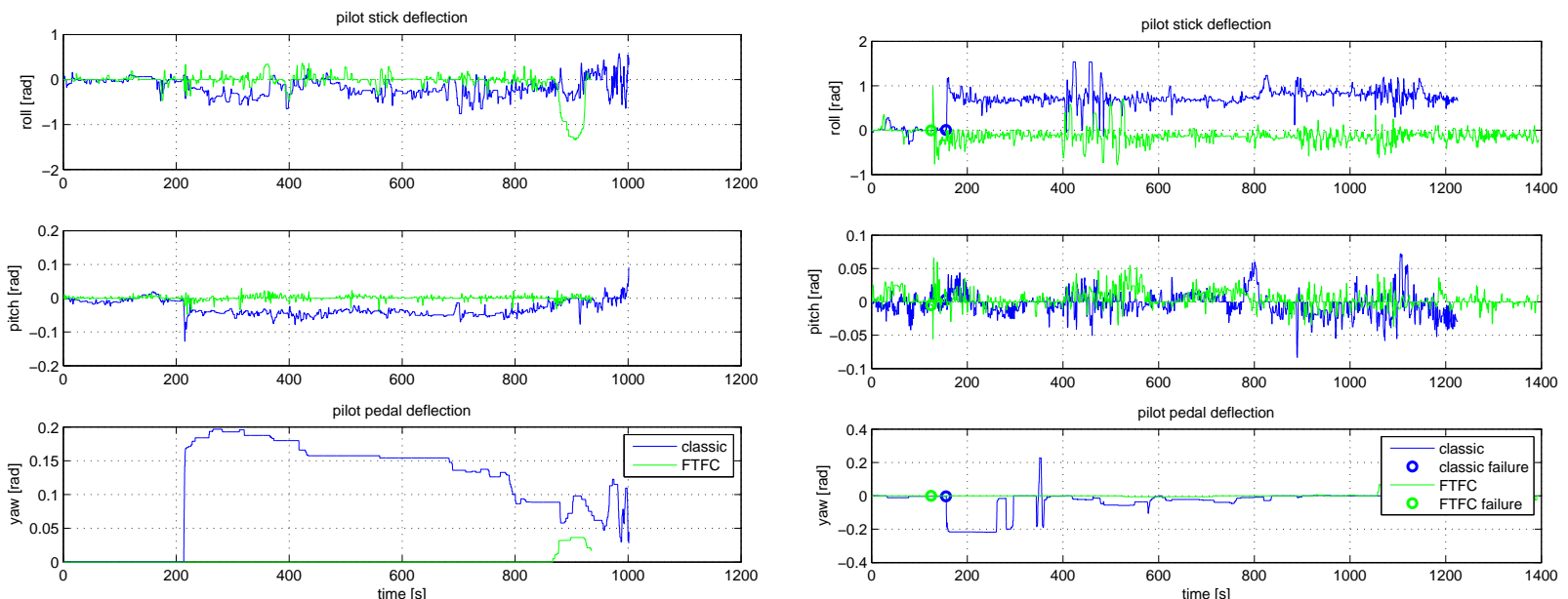

(c) engine separation scenario

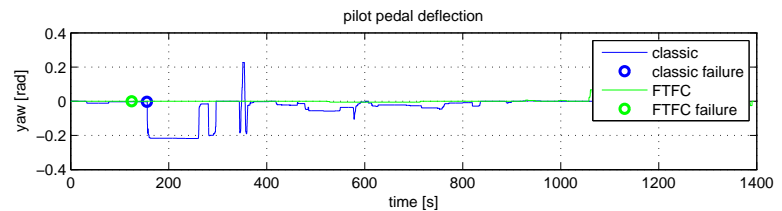

(d) rudder runaway

Figure 7. The pilot control actions during the different scenarios which were flown manually. Range of available pilot control deflections: roll $\pm 1.536 \mathrm{rad}$, pitch $\pm 0.221 \mathrm{rad}$, yaw $\pm 0.244 \mathrm{rad}$ 
aircraft again, but altitude and speed conditions do not allow anymore to line up the aircraft successfully with the runway.
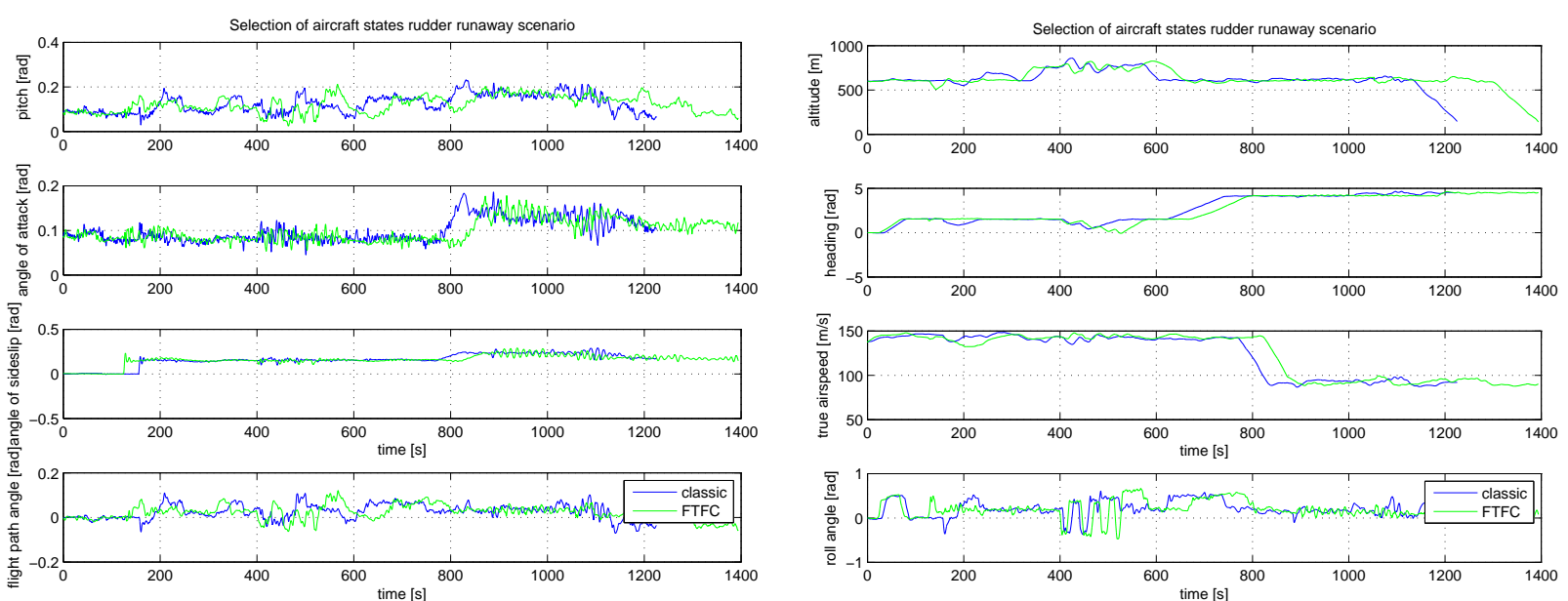

Figure 8. Comparison of a selection of aircraft states for the rudder runaway scenario
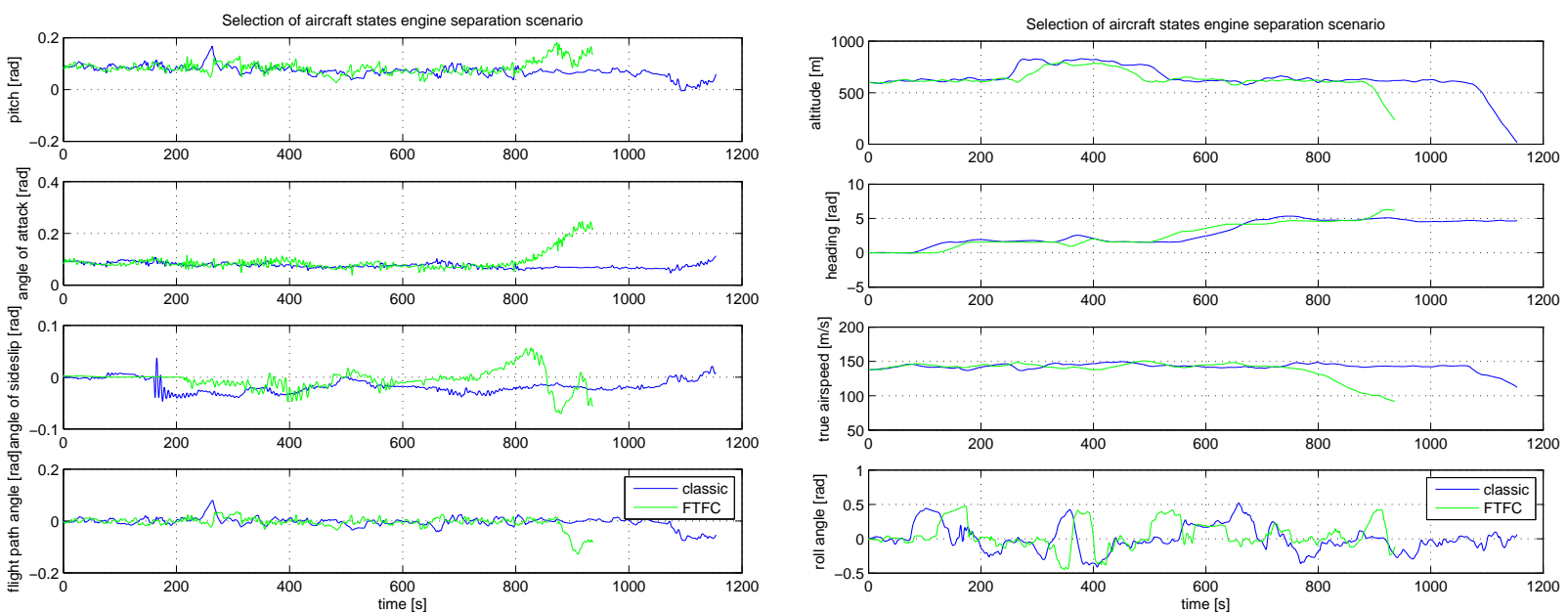

Figure 9. Comparison of a selection of aircraft states for the engine separation scenario

Fig. 10 shows the time histories of the control surface deflections for the different scenarios. These graphs confirm that the ANDI-controller uses the remaining active control surfaces in a way similar to what a human pilot would do. In fig. 10(b), it is clear that the disturbing influence of the stabilizer runaway is counteracted by means of the elevators, however, without command from the pilot as can be seen in fig. 7(b). The same principle holds for the other scenarios. Recall that for the engine separation scenario, inner ailerons are only half operational, supported by the remaining spoilers, as already announced by the damage information in fig. 1, and this is also visible in fig. 10(c). A significant difference in rudder deflection is visible between the Classic and FTFC cases in Figure 10(c). This illustrates that the FTFC algorithm exploits the full control authority of the rudder, where the human pilot relies less on rudder control input. As a consequence, slightly less aileron deflections are needed in the FTFC case compared to classic control. The balance between aileron and rudder use can be improved by means of control allocation. Another difference is visible in the elevator deflection for the rudder runaway scenario. This is the auto-trim feature of the elevator which contributes if the stabilizer is not set properly according to the speed regime, as is also visible in the nominal case in fig. 10(a). Future research in control allocation will optimize the balance between the use of the different control surfaces. For the rudder runaway scenario in fig. 10(d), the faulty rudder behavior illustrates the 
aerodynamic blowdown effect which is taken into account in the RECOVER simulation model. As a result the maximum rudder deflection is slightly below $15^{\circ}$ for an airspeed around $270 \mathrm{knots}$, and even close to $25^{\circ}$ (the physical maximum deflection limit imposed by the rudder control system structure) for an airspeed of 165 knots.
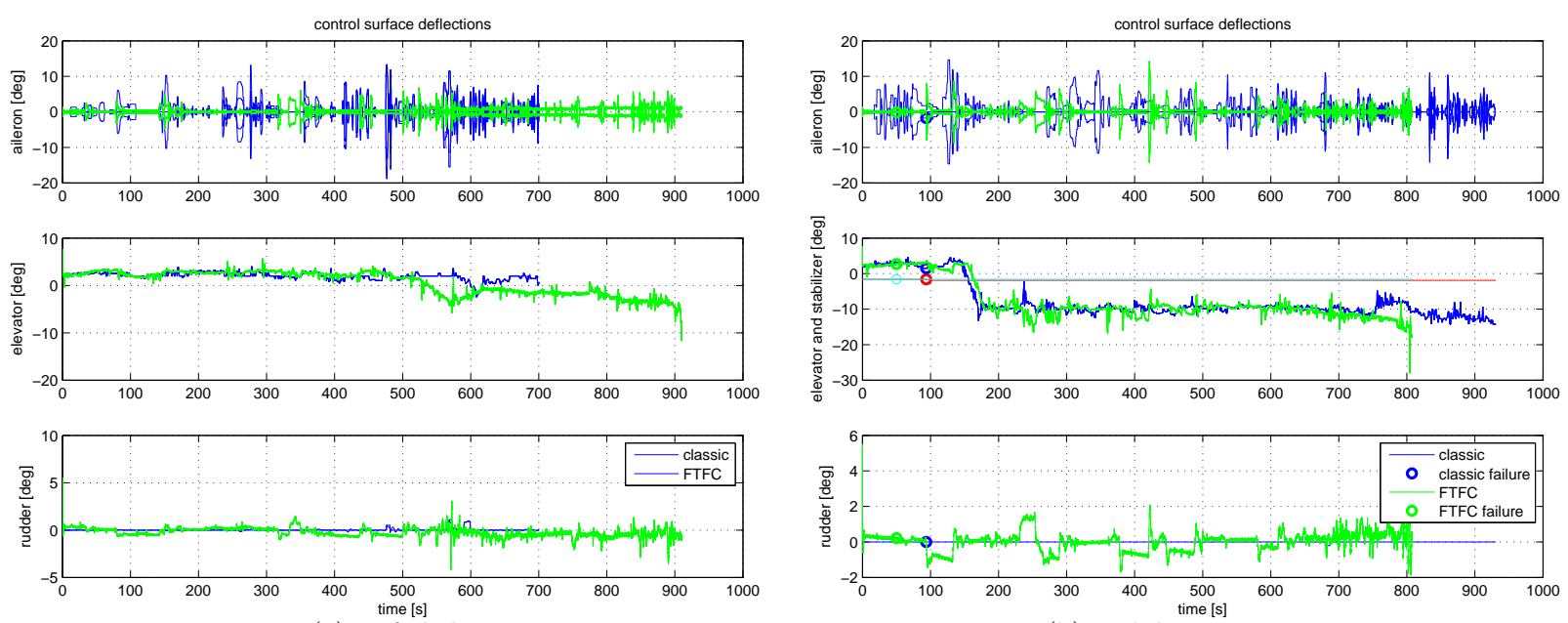

(a) unfailed

(b) stabilizer runaway
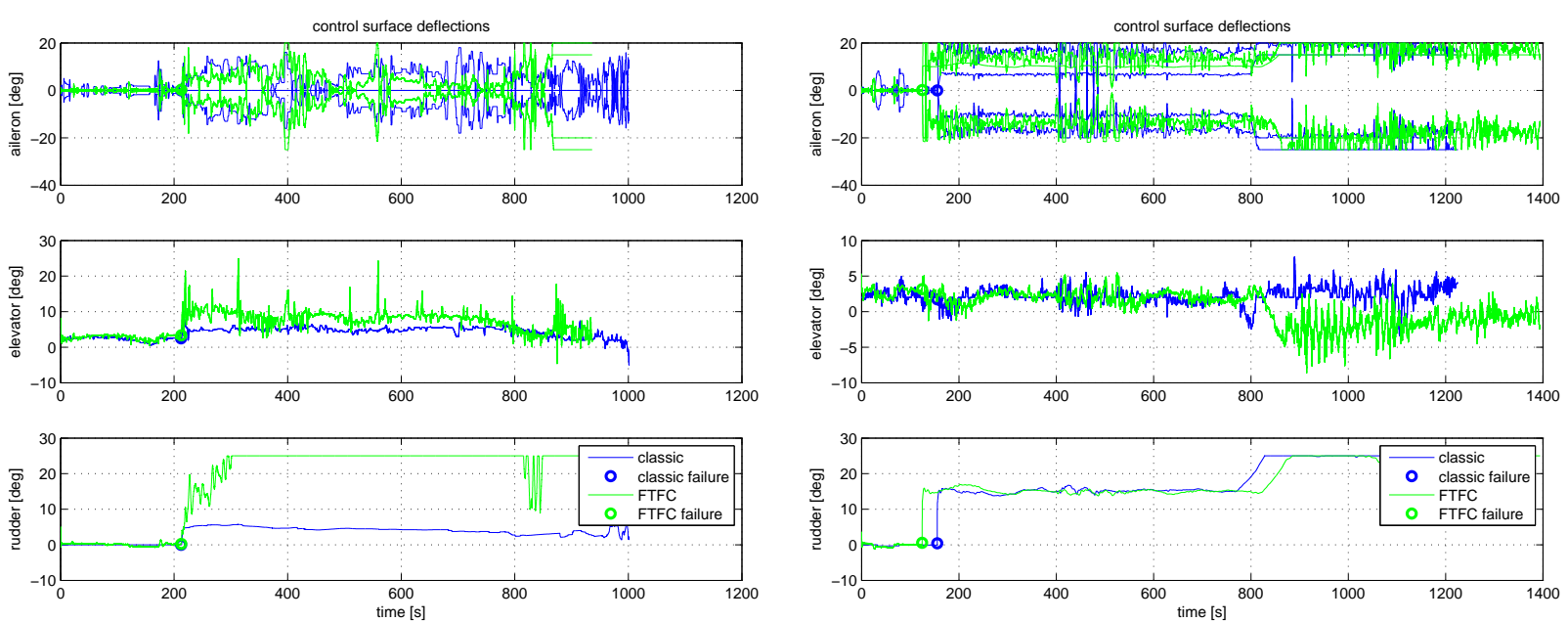

(c) engine separation scenario

(d) rudder runaway

Figure 10. Time histories of the control surface deflections involved in the different scenarios which were flown manually

Based upon these simulation runs, handling qualities as well as pilot workload have been analysed, as is shown next. Simulations have shown that the stabilizer runaway was the least challenging from a pilot point of view, as explained earlier. Therefore, the subsequent discussions focus primarily on engine separation and rudder hardover, since these are the most interesting scenarios from a pilot point of view. 


\section{B. Handling qualities analysis results: $\mathrm{CH}$ ratings}

The handling qualities results for the algorithm show that, especially for the El Al Flight 1862 scenario, conventional flight control was restored to acceptable levels while physical and mental workload were reduced significantly. This is illustrated in Figure 11 where an example is given of lateral handling quality pilot ratings for the localizer capture task. It can be seen that, for this task, both the baseline and fault-tolerant fly-by-wire (FBW) aircraft were rated Level 1 (Rating 1-3). After separation of the right-wing engines (Figure 11), lateral handling qualities degraded to Level 2 for the conventional aircraft with the classical control system. The reconfigured aircraft (FBW) shows about Level 1 handling qualities after incurring significant damage due to the loss of the right-wing engines. This was substantiated by measured pilot control activities, representative of workload, indicating no pilot compensation after reconfiguration. For the rudder runaway failure, however, Level 2 handling qualities remained after reconfiguration despite no required pilot compensation (Figure 7(d)). The difference was most probably caused by not utilizing differential thrust for reconfiguration to compensate for the yawing moment. As a consequence, a constant non-zero roll or sideslip angle was needed in order to re-establish equilibrium. This attitude was disturbing, especially since no corresponding pilot actions were needed.

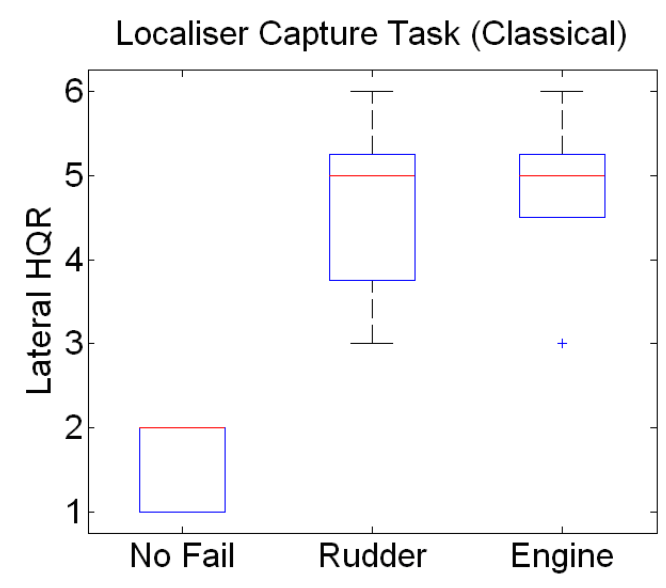

(a) classical control

\section{Localiser Capture Task (FBW)}

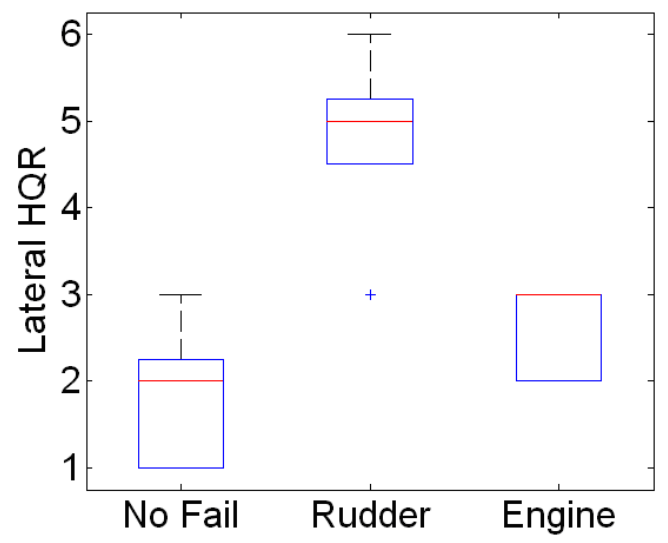

(b) fault tolerant control

Figure 11. Localizer capture task handling qualities ratings for classical control and fault tolerant control

\section{Pilot work analysis results}

Handling quality ratings are only one means to evaluate the performance of a flight control system, and despite use of the Cooper Harper Rating Scale, they still involve some pilot subjectivity, although this is eliminated as much as possible. On the other hand, there is the quantifiable pilot workload analysis. This subsection focuses on the latter part of the study.

Specific metrics exist in order to analyse the specific workload properties of a flight control system, excluding possible secondary influences, like the control loading system characteristics, as described in section 3. In addition, these quantities allow a separation between two different types of workload, namely physical workload and compensatory workload. The former is the workload related to the physical effort a pilot has to exert, and is represented by average force and root mean square of the pilot control deflections, as illustrated in section 1 . The latter is the workload related to the steering task itself, which is rather a mental load. This one can be observed by analysing the root mean square of the pilot control deflection rates or the pilot control power, as done in section 2 .

This pilot workload figures have been calculated for two different phases, namely the specific part of the localizer intercept phase (left), which is defined as the time span between the triggering of the LOC valid flag and the GS valid flag, and secondarily the total simulation run (right). For the latter, the time span 
is defined as follows. Unfailed situations are considered from start to end of the simulation run. Scenarios including failures are restricted to the time span after the failure till the end. The localizer intercept phase work levels are comparable, since the time intervals are almost identical, thanks to the well-defined start and end points and the prescribed airspeed and trajectory. However, for the total simulation run, there are considerable variations in the time span from beginning till end, as can be seen in figures 7 and 10 , which makes the absolute workload values not comparable. Therefore, average workload levels have been calculated for the total simulation run. In each graph, a distinction is made between roll, pitch and yaw channel, as illustrated by the three graphs separated vertically. In each control channel, six cases have been studied, namely unfailed, engine separation and rudder runaway, each time with classical and fault tolerant control. In each case, the workload figure of each of the five pilots is represented individually by means of bar plots, after which the mean and standard deviations are superimposed on these bar plots for every case, in order to facilitate mutual comparisons. Mind that no data are available for pilot 1 in the localizer intercept phase for the engine separation failure with fault tolerant controller, this is because the safe flight envelope boundary has been exceeded before the GS valid flag was raised, leading to unreliable results since they are not representative.

\section{Physical workload}

The physical workload quantifies the physical effort levels a pilot has to exert in order to accomplish the requested mission profile. This workload can be represented in the first place by the average value of the absolute forces and alternatively by the root mean square of the pilot control deflections, as follows:

$$
R M S_{\text {defl }}=\frac{\left\|\delta_{\text {ctrl }}\right\|_{2}}{\sqrt{n}}
$$

where $\delta_{\text {ctrl }}$ is the pilot control deflection under consideration and $n$ is the length of the recorded data sample. Mind that both measures are set up in such a way that variations in data sample lengths are automatically taken into account, which is important for the total simulation run data. Figures 12 and 13 illustrate the physical workload analysis results in the presentation as was introduced earlier. Figure 12 depicts the average pilot forces, and figure 13 portrays the root mean square of the pilot control deflections.
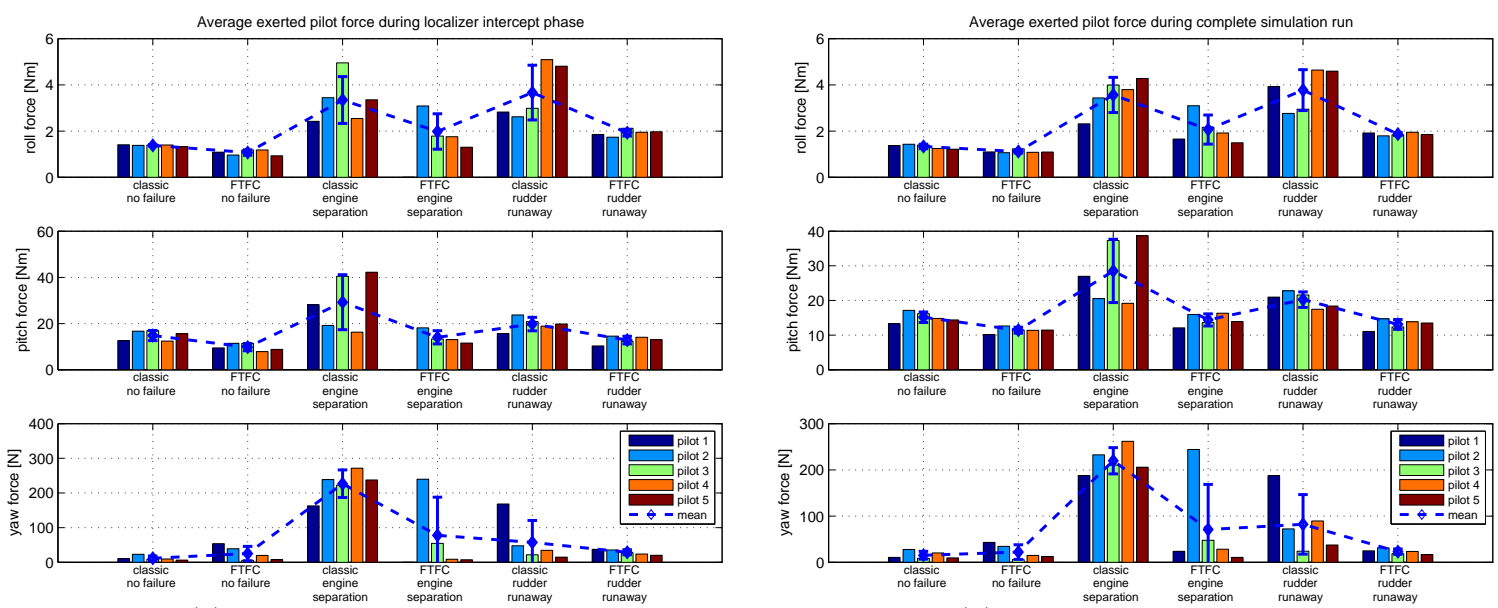

(a) localizer intercept phase

(b) complete simulation run

Figure 12. Total average pilot force during localizer intercept phase (left) and during complete simulation run (right)

Both figures lead to the same observations. First of all, the unfailed conditions confirm that this is a good comparison basis between classic and FTFC, since both have the same ratings. Comparing classic control with FTFC for failed configurations shows that overall values over all pilots for average force as well as RMS for deflections decrease for FTFC in the failure scenarios. In addition, the standard deviations also reduce from classic control towards FTFC in the failure scenarios, pointing out more consistency. Only the 

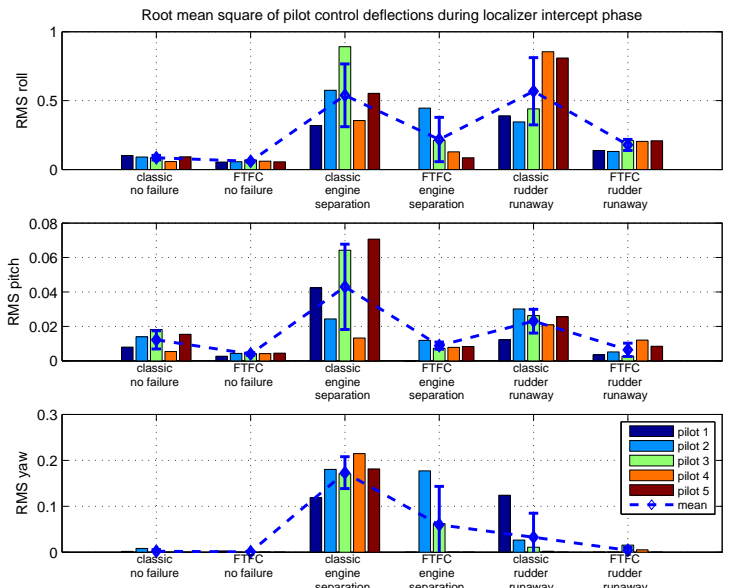

(a) localizer intercept phase
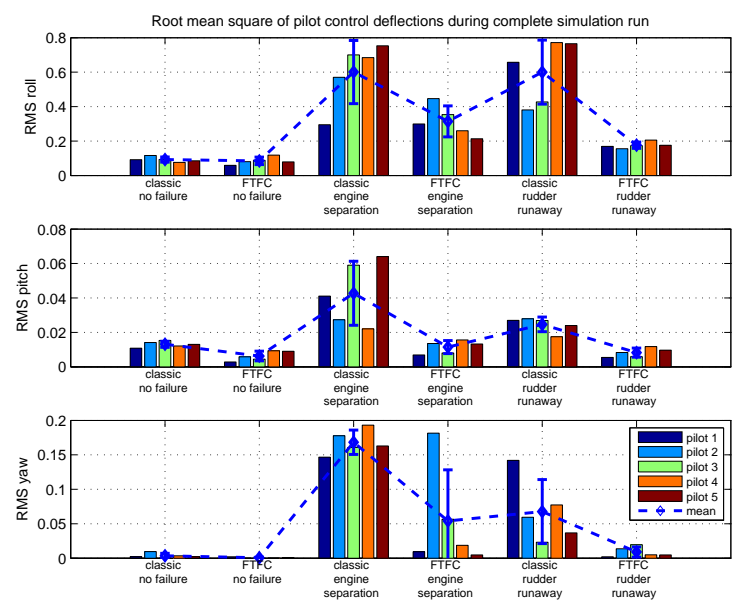

(b) complete simulation run

Figure 13. Root mean square of pilot control deflections during localizer intercept phase (left) and during complete simulation run (right)

yaw force for the engine separation case is an exception to this trend, but there can be seen that test pilot 2 exhibits a significantly deviating behavior with a high and above-average steering force compared to the other subjects. His behavior causes the increase in the standard deviation compared with the classic controller. At the end of the simulation run, it turned out that this deviating performance of pilot 2 was caused by a misunderstanding about the steering principle of the controller, since he was not aware that pedals in fact control sideslip angle directly through the fault tolerant controller. Finally, searching for overlap of the errorbars between classic and FTFC shows that this overlap occurs only minimally for the roll force in the engine separation scenario, and only in the LOC intercept phase. This observation makes the trends clearly significant, despite the limited number of experiment subjects.

Summarizing, it can be stated that average absolute force as well as pilot control deflections RMS confirm that the FTFC reduces the physical workload considerably, compared to classical control.

\section{Compensatory workload: RMS of pilot control deflections}

Visualisation of the compensatory workload, which is an indication of the correcting and stabilizing efforts of the pilot, is less straightforward. The most frequently used variable to quantify this type of workload, is the RMS of the pilot control deflection rates. These have been calculated and are presented in fig. 14 .

These results show no decisive confirmation about any changes in the workload. This can be partly explained by the nature of the experiment. In order to be able to draw the right conclusions about the compensatory workload based upon the RMS of the deflection rates, one needs to make the test pilots feel familiar with the system. Because of a lack of training in these specific experiments and the absence of repetitions, this causes a lot of spread in the data, as can be seen in the relatively large standard deviations in fig. 14. Each pilot was still in the process of determining his control strategy, which differs from pilot to pilot. With enough experience, after sufficient repetitions, these control strategies would converge again. Nevertheless, including more training for the pilots disagrees with the setup of the experiment to confront untrained and unprepared pilots with the failures. Another aspect is the fact that the FTFC's outer loop control was not yet rigorously optimized for handling qualities and improvements can be expected in later iterations. An alternative and more appropriate monitoring variable for the compensatory workload in this setup is the pilot power level, which is again averaged over the time interval considered for the total 

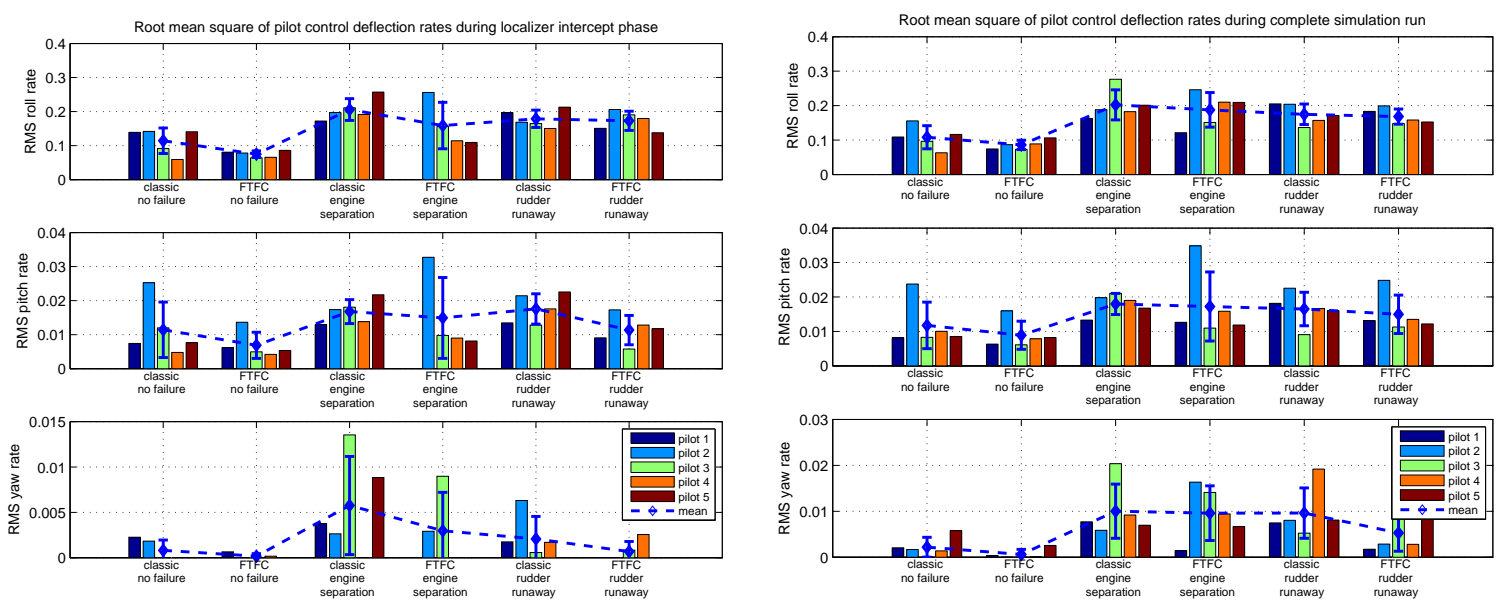

(a) localizer intercept phase

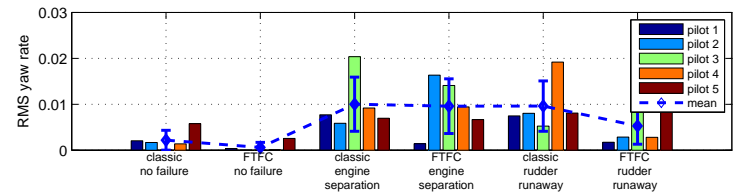

(b) complete simulation run

Figure 14. Root mean square of pilot control deflection rates during localizer intercept phase (left) and during complete simulation run (right)

simulation run scenarios. Pilot power values have been calculated as follows:

$$
\begin{aligned}
P & =\int_{t=t_{0}}^{t_{\mathrm{end}}} F(t) \cdot \frac{d \delta_{\mathrm{ctrl}}(t)}{d t} d t \\
P_{\mathrm{av}} & =\frac{1}{T_{\mathrm{tot}}} \int_{t=t_{0}}^{t_{\mathrm{end}}} F(t) \cdot \frac{d \delta_{\mathrm{ctrl}}(t)}{d t} d t
\end{aligned}
$$

These power values are depicted in fig. 15 .
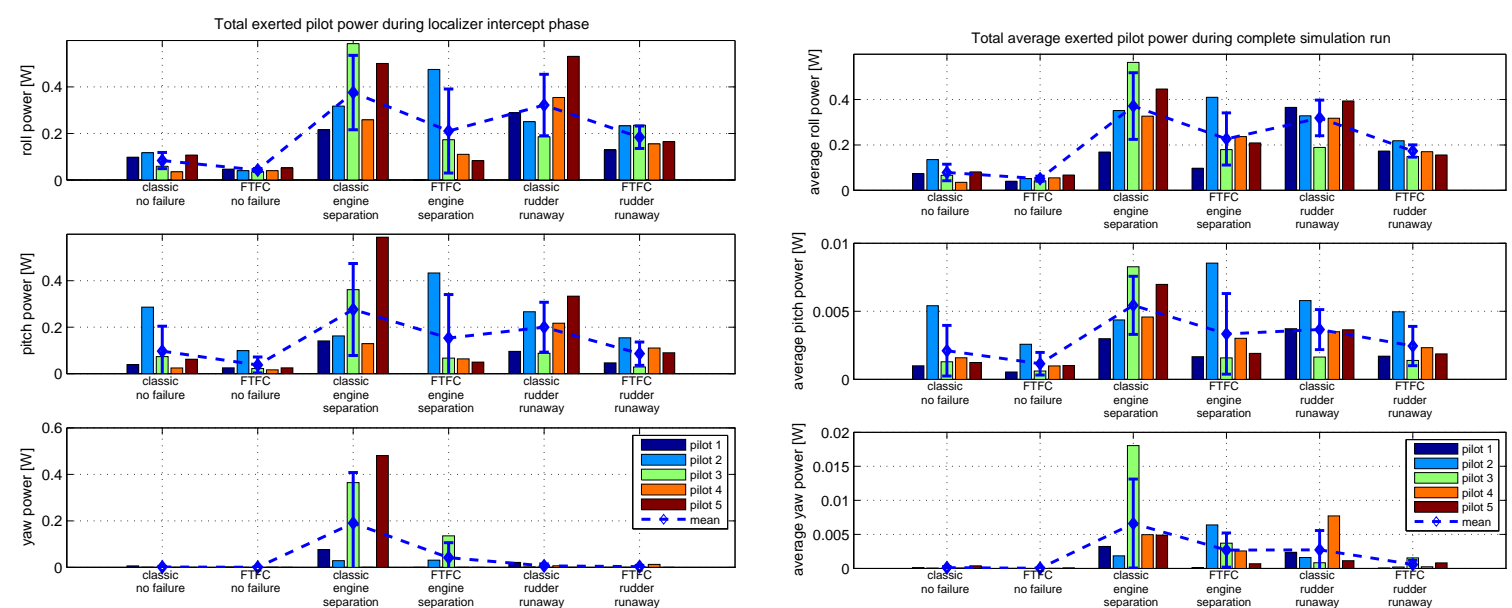

(a) localizer intercept phase

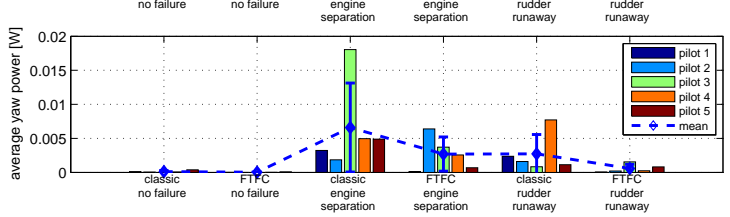

(b) complete simulation run

Figure 15. Average pilot power during localizer intercept phase (left) and during complete simulation run (right)

Although not as decisive as for the physical workload, the trends are still clear. The unfailed conditions confirm that this is a good comparison basis between classic and FTFC, since both have the same ratings. Overall (average) power values decrease for FTFC in failed situations, but the standard deviations show once again more variation between the performances of the test subjects. Nevertheless, also here pilot 2 is a clear outlier compared to the other pilots for the FTFC engine separation case. Ignoring the data of pilot 
2 reveals more consensus between the subjects. The yaw power values should be zero in the rudder failure case, since the pedals have no effective use in this failure case. As a matter of fact, the pilots still had the natural intuitive tendency to use the pedals to compensate for the disturbance (despite briefing them on the nature of the injected failure). Some pilots realized this fact after a while, others were aware of it from the start. As a consequence, some yaw power values are zero where others are nonzero but still relatively small.

In summary, there are indications that the pilot's compensatory workload is also made easier by the fault tolerant control, although these indications may not be as decisive as for his physical workload. It should be noted that this manual FTFC algorithm has not yet been fully optimized for HQ ratings. This is partly the reason for these less clear observations. As a final remark, it can be noted that all workload assessment figures confirm a clear improvement in both types of pilot workload increase for the rudder runaway scenario, although this is not clear from the pilot's appreciation through the Cooper Harper Handling Qualities assessment. It is believed that this is caused by the somehow unnatural and disturbing attitude of the aircraft post-failure, including non-zero bank and sideslip angle. Most likely, the reason for the lower rating is caused by the fact that the fault tolerant controller is a rate controller, it minimizes disturbed angular rates, but not the disturbed angle itself. A possible solution for this is the implementation of a rate control attitude hold algorithm, as shown in fig. 16. The beneficial effect of this feature can possibly be tested in a new campaign.

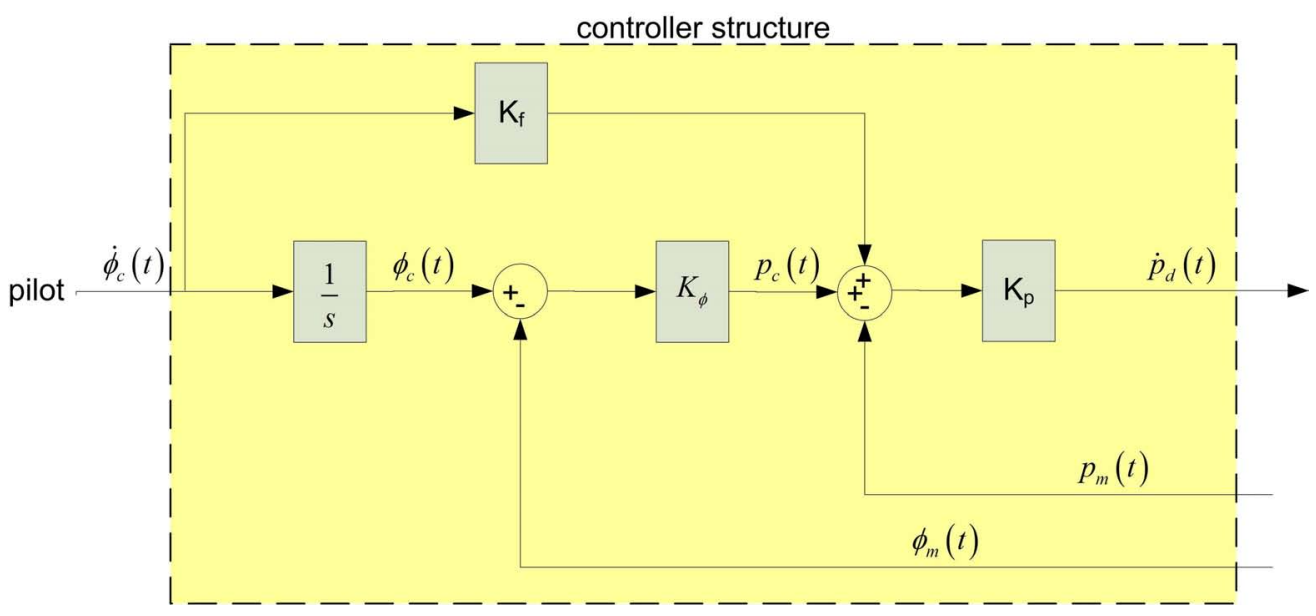

Figure 16. Input structure setup for a rate control attitude hold controller

\section{Concluding remarks}

In conclusion, it can be stated that, following physical experiments on the SIMONA Research Simulator, the manually operated model based nonlinear reconfiguring control algorithm, including a real time aircraft model identification routine, has been shown to be successful in recovering the ability to control damaged aircraft. The designed methods are capable of accommodating the damage scenarios which have been investigated in this paper. Simulation results have shown that the handling qualities of the fault tolerant controller devaluate less for most failures. Moreover, it has been found that the average increase in workload after failure is considerably reduced for the fault tolerant controller, compared to the classical controller. Finally, standard deviations become smaller for the fault tolerant controller, pointing out more consistency among test subjects. These observations apply for physical as well as compensatory (mental) workload.

\section{Acknowledgments}

This research was supported by the Dutch Technology Foundation (STW) under project number 06515. Furthermore, the authors would like to thank the five simulator test pilots for participating in this experiment. Finally, Herman Damveld, Mark Mulder and Rene Van Paassen are acknowledged for their technical support during the experiments and their valuable contributions for the correct analysis of the data. 


\section{References}

1 "Civil Aviation Safety Data," Tech. rep., Civil Aviation Authority of the Netherlands (CAA-NL), 2003.

${ }^{2}$ Smaili, M., Breeman, J., Lombaerts, T., and Joosten, D., "A Simulation Benchmark for Integrated Fault Tolerant Flight Control Evaluation," AIAA Modeling and Simulation Technologies Conference and Exhibit, No. AIAA-2006-6471, Keystone, CO, August 2006.

${ }^{3}$ Patton, R., "Fault Tolerant Control Systems: The 1997 situation," Proceedings of IFAC Symposium on SAFEPROCESS, HULL, UK, August 1997, pp. 1033-1055.

${ }^{4}$ Zhang, Y., "Fault Tolerant Control Systems: Historical Review and Current Research," CRAN, France, 2005.

${ }^{5}$ Zhang, Y. and Jiang, J., "Bibliographical Review on Reconfigurable Fault-Tolerant Control Systems," 5th IFAC Symposium on Fault Detection, Supervision and Safety for Technical Processes, Washington DC, USA, June 9-11 2003, pp. 265-275. 1999.

6 "Intelligent Flight Control: Advanced Concept Program," Final Report BOEING-STL 99P0040, The Boeing Company,

${ }^{7}$ Ganguli, S., Papageorgiou, G., Glavaski, S., and M., E., "Piloted Simulation of Fault Detection, Isolation and Reconfiguration Algorithms for a Civil Transport Aircraft," AIAA Guidance, Navigation and Control Conference and Exhibit, No. AIAA-2005-5936, San Francisco, CA, August 2005.

${ }^{8}$ Corvin, J. H., Havern, W. J., Hoy, S. E., Norat, K. F., Urnes, J. M., and Wells, E. A., "Self-Repairing Flight Control Systems, Volume I: Flight Test Evaluation on an F-15 Aircraft," Final Report WL-TR-91-3025, 1991.

${ }^{9}$ KrishnaKumar, K. and Gundy-Burlet, K., "Intelligent Control Approaches for Aircraft Applications," Tech. rep., NeuroEngineering Laboratory, NASA Ames Research Center.

${ }^{10}$ Brinker, J. and Wise, K., "Nonlinear Simulation Analysis of a Tailless Advanced Fighter Aircraft Reconfigurable Flight Control Law," AIAA Guidance, Navigation and Control Conference and Exhibit, No. AIAA-99-4040, Portland, OR, August 1999.

${ }^{11}$ Calise, A. J., Lee, S., and Sharma, M., "Development of a Reconfigurable Flight Control Law for the X-36 Tailless Fighter Aircraft," AIAA Journal of Guidance, Control and Dynamics, Vol. 24, No. 5, 2001, pp. 896-902.

${ }^{12}$ Hallouzi, R. and Verhaegen, M., "Reconfigurable Fault Tolerant Control of a Boeing 747 using Subspace Predictive Control," AIAA Guidance, Navigation and Control Conference and Exhibit, No. AIAA-2007-6665, Hilton Head,SC, August 2007.

${ }^{13}$ Joosten, D., van den Boom, T., and Lombaerts, T., "Effective control allocation in fault-tolerant flight control with MPC and feedback linearization," Proceedings of the European Conference on Systems and control, Kos, Greece, July 2007, pp. $3552-3559$

${ }^{14}$ van Kampen, E., Chu, Q., and Mulder, J., "Continuous Adaptive Critic Flight Control Aided with Approximated Plant Dynamics," AIAA Guidance, Navigation and Control Conference and Exhibit, No. AIAA-2006-6429, Keystone, CO, August 2006.

${ }^{15}$ Sonneveldt, L., Chu, Q., and Mulder, J., "Constrained Adaptive Backstepping Flight Control: Application to a Nonlinear F-16/MATV Model," AIAA Guidance, Navigation and Control Conference and Exhibit, No. AIAA-2006-6413, Keystone, CO, August 2006.

${ }^{16}$ Sonneveldt, L., van Oort, E., Chu, Q., and Mulder, J., "Inverse Optimal Nonlinear Adaptive Missile Autopilot Design," AIAA Guidance, Navigation and Control Conference and Exhibit, No. AIAA-2007-6675, Hilton Head, SC, August 2007.

${ }^{17}$ van Oort, E., Sonneveldt, L., Chu, Q., and Mulder, J., "Modular Adaptive Input-to-State Stable Backstepping of a Nonlinear Missile Model," AIAA Guidance, Navigation and Control Conference and Exhibit, No. AIAA 2007-6676, Hilton Head, SC, August 2007.

${ }^{18}$ De Weerdt, E., Chu, Q., and Mulder, J., "Neural Network Aerodynamic Model Identification for Aerospace Reconfiguration," AIAA Guidance, Navigation and Control Conference and Exhibit, No. AIAA-2005-6448, San Francisco, CA, August 2005.

${ }^{19}$ Brinker, J. S. and Wise, K. A., "Flight testing of reconfigurable control law on the X-36 tailless aircraft," Journal of Guidance, Control and Dynamics, Vol. 24, No. 5, September-October 2001, pp. 903-909.

${ }^{20}$ Smaili, M., Breeman, J., and Lombaerts, T., "A Simulation Benchmark for Aircraft Survivability Assessment," 26th International Congress of the Aeronautical Sciences, No. ICAS 2008-9.3.2, Anchorage, AK, 2008.

${ }^{21}$ Marcos, A. and Balas, G., "A Boeing 747-100/200 Aircraft Fault Tolerant and Fault Diagnostic Benchmark," Technical Report AEM-UoM-2003-1, June 2003.

${ }^{22}$ Szaszi, I., Ganguli, S., Marcos, A., Balas, G. J., and Bokor, J., "Application of FDI to a Nonlinear Boeing 747 Aircraft," 10th Mediterranean Conference on Control and Automation, Lisbon, Portugal, July 2002.

${ }^{23}$ Maciejowski, J. and Jones, C., "MPC Fault Tolerant Flight Control Case Study: Flight 1862," IFAC Safeprocess Conference, 2003.

${ }^{24}$ Lombaerts, T., Breeman, J., Joosten, D., van den Boom, T., Chu, Q., Mulder, J., and Verhaegen, M., "Specifications modelling document for Garteur AG16 fault tolerant control," Tech. rep., Delft University of Technology, 2005.

${ }^{25}$ Lombaerts, T., Joosten, D., J.H.Breemand, Smaili, H., Chu, Q., van den Boom, T., Mulder, J., and Verhaegen, M., "Assessment criteria as specifications for reconfiguring control," proceedings of the AIAA Guidance, Navigation, and Control Conference and Exhibit, No. AIAA-2006-6331, Keystone, CO, August 2006.

${ }^{26}$ Joosten, D., van den Boom, T., and Lombaerts, T., "Fault-tolerant control using dynamic inversion and model-predictive control applied to an aerospace benchmark," the Proceedings of the 17th IFAC world congress, 2008, Accepted for presentation at the IFAC world congress.

${ }^{27}$ Cieslak, J., Henry, D., Zolghadri, A., and Goupil, P., "Development of an active fault-tolerant flight control strategy," AIAA Journal of Guidance, Control and Dynamics, Vol. 31, 2008, pp. 135-147.

${ }^{28}$ Hallouzi, R. and Verhaegen, M., "Fault-Tolerant Subspace Predictive Control Applied to a Boeing 747 model," AIAA Journal of Guidance, Control and Dynamics, Vol. 31, 2008, pp. 873-883. 
${ }^{29}$ Alwi, H., Edwards, C., Stroosma, O., and Mulder, J., "Fault Tolerant Sliding Mode Control Design with Piloted Simulation Evaluation," AIAA Journal of Guidance, Control and Dynamics, Vol. 31, 2008, pp. 1186-1201.

${ }^{30}$ Varga, A., "Design of Least Order Residual Generators for Fault Detection and Isolation with Application to Monitoring Actuator/Surface Faults for a Boeing 747 100/200 Aircraft," 2008, DLR IB 515-08-28.

${ }^{31}$ Varga, A., "Fault detection and isolation of actuator failures for a large transport aircraft," CEAS 2007, 2007.

${ }^{32}$ Edwards, C., Lombaerts, T., and Smaili, M., Fault tolerant control a benchmark challenge, Lecture Notes in Control and Information Sciences, Springer-Verlag, 2008, To be published.

${ }^{33}$ Lombaerts, T., Huisman, H., Chu, Q., Mulder, J., and Joosten, D., "Nonlinear Reconfiguring Flight Control based on On-line Physical Model Identification," AIAA Journal of Guidance, Control and Dynamics, 2009, accepted for publication.

${ }^{34}$ Mulder, J., Design and evaluation of dynamic flight test manoeuvers, Ph.D. thesis, TU Delft, Faculty of Aerospace Engineering, 1986.

${ }^{35}$ Chu, Q., Lecture Notes AE4-394, Modern Flight Test Technologies and System Identification, Delft University of Technology, Faculty of Aerospace Engineering, 2007.

${ }^{36}$ Laban, M., On-Line Aircraft Aerodynamic Model Identification, Ph.D. thesis, Delft University of Technology, May 1994.

${ }^{37}$ Mulder, J., Chu, Q., Sridhar, J., Breeman, J., and Laban, M., "Non-linear aircraft flight path reconstruction review and new advances," Progress in Aerospace Sciences, Vol. PIAS 35 (1999) 673-726, 1999.

${ }^{38}$ Jategaonkar, R., Flight Vehicle System Identification: A Time Domain Methodology, Vol. 216 of Progress in Astronautics and Aeronautics Series, AIAA, 1st ed., 2006.

${ }^{39}$ Morelli, E., "Real-Time Parameter Estimation in the Frequency Domain," Journal of Guidance, Control and Dynamics, Vol. 23, No. 5, 2000, pp. 812-818.

${ }^{40} \mathrm{Chu}$, Q., Mulder, J., and Sridhar, J., "Decomposition of Aircraft State and Parameter Estimation Problems," Proceedings of fhe 10th IFAC Sympium on System Identifiation, Vol. Vol. 3, pp. 61-66, 1994.

${ }^{41}$ Campa, G., Seanor, B., Gu, Y., and Napolitano, M. R., "NLDI Guidance Control Laws for Close Formation Flight," American Control Conference, Portland, OR, USA, June 8-10 2005.

${ }^{42}$ Reiner, J., Balas, G. J., and Garrard, W. L., "Flight Control Design Using Robust Dynamic Inversion and Time-scale Separation," Automatica, Vol. 32, No. 11, 1996, pp. 1493-1504.

${ }^{43}$ Ramakrishna, V., Hunt, L., and Meyer, G., "Parameter variations, relative degree, and stable inversion," Automatica, Vol. 37, 2001, pp. 871-880.

${ }^{44}$ Ostroff, A. J. and Bacon, B. J., "Enhanced NDI strategies for reconfigurable flight control," Proceedings of the American Control Conference, Anchorage, AK, May 8-10 2002.

${ }^{45}$ Slotine, J.-J. E. and Li, W., Applied Nonlinear Control, Prentice Hall, 1991.

${ }^{46}$ Cooper, G. and Harper, R. J., "The Use of Pilot Rating in the Evaluation of Aircraft Handling Qualities," Tech. Rep. TN D-5153, NASA, 1969.

${ }^{47}$ Van Paassen, M. and Stroosma, O., "DUECA - Data-Driven Activation in Distributed Real-Time Computation," AIAA Modeling and Simulation Conference and Exhibit, No. AIAA-2000-4503, AIAA, August 2000.

${ }^{48}$ Stroosma, O., Van Paassen, M., and Mulder, M., "Using the SIMONA Research Simulator for Human-Machine Interaction Research," AIAA Modeling and Simulation Conference and Exhibit, No. AIAA-2003-5525, August 2003.

${ }^{49}$ Smaili, M., "Flight Data Reconstruction and Simulation of the 1992 Amsterdam Bijlmermeer Airplane Accident," AIAA Modeling and Simulation Conference and Exhibit, No. AIAA-2008-4586, AIAA, August 2000.

${ }^{50}$ Smaili, M., Flight Data Reconstruction and Simulation of El Al Flight 1862, Master's thesis, Delft University of Technology, November 1997. 